\title{
WestVirginiaUniversity
}

THE RESEARCH REPOSITORY @ WVU

Graduate Theses, Dissertations, and Problem Reports

2000

\section{Dynamical analysis of infant social referencing}

\author{
Melissa Sue Atkins \\ West Virginia University
}

Follow this and additional works at: https://researchrepository.wvu.edu/etd

\section{Recommended Citation}

Atkins, Melissa Sue, "Dynamical analysis of infant social referencing" (2000). Graduate Theses, Dissertations, and Problem Reports. 738.

https://researchrepository.wvu.edu/etd/738

This Thesis is protected by copyright and/or related rights. It has been brought to you by the The Research Repository @ WVU with permission from the rights-holder(s). You are free to use this Thesis in any way that is permitted by the copyright and related rights legislation that applies to your use. For other uses you must obtain permission from the rights-holder(s) directly, unless additional rights are indicated by a Creative Commons license in the record and/ or on the work itself. This Thesis has been accepted for inclusion in WVU Graduate Theses, Dissertations, and Problem Reports collection by an authorized administrator of The Research Repository @ WVU. For more information, please contact researchrepository@mail.wvu.edu. 


\title{
Dynamical Analysis of Infant Social Referencing
}

\author{
Melissa S. Atkins
}

\author{
Thesis submitted to the Eberly College \\ Of Arts and Sciences at \\ West Virginia University \\ In partial fulfillment of the requirements \\ For the degree of
}

\author{
Master of Arts \\ In \\ Psychology
}
Anne C. Watson, Ph.D., Chair
Tracy L. Morris, Ph.D.
Hayne W. Reese, Ph.D.

Department of Psychology

\section{Morgantown, West Virginia}

2000

Keywords: Social referencing, social cognition, dynamical analysis 


\section{ABSTRACT \\ Dynamical Analysis of Infant Social Referencing}

\section{Melissa S. Atkins}

The purpose of the present study was to examine relations between joint attention, language, maternal sensitivity, and temperament and the emergence of social referencing in infants and to closely observe variability in social referencing behavior at the end of the first year. Five infants, 7 months of age, were observed on a weekly basis for a period of four months. All five infants were engaging in social referencing behavior at the beginning of the study, which is much earlier than the literature indicates; therefore, the onset of the behavior was missed. However, results did indicate variability in social referencing behavior, in that infants referenced more in the laboratory than at home, more after being picked up by a stranger than when the stranger was approaching, and more when hearing a noise for the first time than when hearing that noise the second time. Results also showed an emergent pattern of behavior in joint attention. 


\section{Acknowledgements}

First, I would like to thank my thesis committee, Drs. Tracy Morris and Hayne Reese, for their useful suggestions and support during this project. I would especially like to thank my chair, Dr. Anne Watson, for her support and encouragement through all aspects of the project. She was a most helpful advisor and I feel honored to have worked under her supervision.

I would also like to thank Britnee McIntyre, Ashley Shafer, and Cathy Thorn for their assistance with the project, which would have been most difficult to complete without their constant efforts. I am also grateful to all of the graduate students who lent their time to act as strangers, and especially to Kristi Barnes, Lesley Cottrell, and Lisa Swenson who dedicated significant amounts of time to assist me in the study.

Finally, I give my thanks to the Department of Psychology Alumni Fund, which funded this project. It would have been most difficult, if not impossible, to complete the study without such funding. 
Abstract

Acknowledgments

iii

List of Tables

vi

List of Figures

vii

Introduction

Social Referencing 2

$\begin{array}{ll}\text { Related Factors } & 7\end{array}$

$\begin{array}{ll}\text { Joint Visual Attention and Pointing } & 7\end{array}$

$\begin{array}{ll}\text { Language } & 7\end{array}$

$\begin{array}{lr}\text { Temperament } & 8\end{array}$

Maternal Sensitivity and the Home Environment $\quad 8$

Task Demands $\quad 9$

$\begin{array}{ll}\text { Ambiguity/Uncertainty } & 9\end{array}$

$\begin{array}{ll}\text { Context } & 10\end{array}$

$\begin{array}{ll}\text { The Present Study } & 10\end{array}$

$\begin{array}{ll}\text { Method } & 11\end{array}$

$\begin{array}{ll}\text { Participants } & 11\end{array}$

$\begin{array}{ll}\text { Instruments and Materials } & 11\end{array}$

$\begin{array}{ll}\text { Language } & 11\end{array}$

Maternal Sensitivity and the Home Environment 13

$\begin{array}{ll}\text { Temperament } & 13\end{array}$

$\begin{array}{ll}\text { Social Referencing } & 14\end{array}$

$\begin{array}{ll}\text { Joint Visual Attention and Pointing } & 15\end{array}$ 
$\begin{array}{ll}\text { Procedures } & 15\end{array}$

$\begin{array}{ll}\text { Language } & 15\end{array}$

Maternal Sensitivity and the Home Environment 15

$\begin{array}{lr}\text { Temperament } & 15\end{array}$

$\begin{array}{ll}\text { Social Referencing } & 15\end{array}$

$\begin{array}{ll}\text { Joint Visual Attention and Pointing } & 18\end{array}$

$\begin{array}{ll}\text { Results } & 19\end{array}$

$\begin{array}{ll}\text { Discussion } & 23\end{array}$

$\begin{array}{ll}\text { Future Directions } & 26\end{array}$

$\begin{array}{ll}\text { References } & 30\end{array}$

Appendix A: Demographics Questionnaire 37

Appendix B: List of Sound Effects and Decibel Levels 43

Appendix C: Social Referencing Data Sheet 45

Appendix D: Joint Attention Data Sheet 46

$\begin{array}{ll}\text { Tables } & 47\end{array}$

$\begin{array}{lr}\text { Figure Captions } & 50\end{array}$

$\begin{array}{ll}\text { Figures } & 52\end{array}$ 


\section{List of Tables}

Table 1: Infants' language comprehension scores as measured by the MCDI and RDLS at ages 7,9 , and 11 months

Table 2: Infants' percentage scores on each dimension of the HOME at times of measurement 1,2 , and 3

Table 3: IBQ scores on dimensions of distress and latency to approach novel stimuli and smiling and laughter at times of measurement 1,2 , and 3 


\section{List of Figures}

Figure 1a: MCDI raw scores $\quad 52$

Figure 1b: Communicative gestures $\quad 53$

Figure 2: Social referencing $\quad 54$

Figure 3: Social referencing stranger paradigm $\quad 55$

Figure 4: Social referencing noise paradigm $\quad 56$

Figure 5: Social referencing context $\quad 57$

Figure 6: Joint visual attention and pointing $\quad 58$

Figure 7: Infant 1 data $\quad 59$

Figure 8: Infant 2 data $\quad 60$

Figure 9: Infant 3 data $\quad 61$

Figure 10: Infant 4 data $\quad 62$

$\begin{array}{ll}\text { Figure 11: Infant } 5 \text { data } & 63\end{array}$ 


\section{Dynamical Analysis of Infant Social Referencing \\ Introduction}

Social referencing has been defined as the process of using another person's interpretive message, or emotional information, about an uncertain situation to form one's own understanding of that situation (Dickstein, Thompson, Estes, Malkin, \& Lamb, 1984; Feinman, 1982; Sorce, Emde, Campos, \& Klinnert, 1985). To some, this means that the individual must seek out the information (Rosen, Adamson, \& Bakeman, 1992), while others state that it can either be sought by or imposed upon the individual (Campos, 1983; Walden \& Baxter, 1989).

Research has shown that infants as young as 10 months of age engage in social referencing (Feinman \& Lewis, 1983; Repacholi, 1998), although most studies indicate that it emerges around one year of age (Baldwin \& Moses, 1996; Mumme, Fernald, \& Herrera, 1996; Rosen, et al., 1992). However, less is known about the path of developmental change in this phenomenon. The purpose of the present study was to closely examine the development of social referencing skills at the end of the human infant's first year, including an examination of potential factors that might interact with its emergence.

Various factors have already been identified as emerging at the same age as social referencing, such as an understanding of causality (Desrochers, Ricard, Decarie, \& Allard, 1994; Kinderman \& Dunbar, 1998), language acquisition (Jenkins \& Astington, 1996), and advances in affect regulation (Walden \& Ogan, 1988). Specifically, during the first year, infants begin to evaluate events and act on their appraisals, engage in more sophisticated social and communicative interactions with caregivers, imitate unfamiliar 
behaviors, and distinguish and appropriately react to emotional expression (Feinman \& Lewis, 1983; Moore \& Corkum, 1994; Nelson, 1999), all of which are involved in social referencing behavior. Although general correlates and transition points have been outlined with respect to social-cognitive development at the end of the human infant's first year, how specific behaviors act together to produce changes in social referencing needs further examination.

\section{$\underline{\text { Social Referencing }}$}

Social referencing relies on three fundamental components: the ability to decode social information, the ability to appreciate the referential quality of social information, and the ability to use appropriate skills to elicit social information (Baldwin \& Moses, 1996). Specifically, in order to use social referencing adaptively, children must be able

to differentiate between emotional expressions of fear, happiness, anger, etc., and respond differentially and appropriately to the meanings of each (Feinman, et al., 1992; Mumme, et al., 1996). Furthermore, infants must recognize that this social information is specific to the ambiguous situation at hand. Finally, in order to obtain emotional information, infants must be able to use the appropriate skills necessary to elicit such information from caregivers (Baldwin \& Moses, 1996). These skills include pointing, assistance seeking, verbal questioning, and looking, all of which are aimed at getting the attention of another. Over time, infants learn that these actions evoke the desired response from their caregivers.

The typical social referencing assessment paradigm involves the following essential elements (Rosen, et al., 1992): presentation of an ambiguous event, an emotional message, and an assessment of infant behavior. The infant, or referrer, is then 
presented with an ambiguous object or event, the referent, to which the caregiver, or referee, responds with an emotional message. The infant, who looks to the caregiver to receive this emotional message, is then observed in order to assess the effect of the message on his or her behavior toward this ambiguous object or event. Ambiguity is very important in these paradigms; the stimulus should elicit attention and interest, but should not evoke either positive or negative affect in the infant (Gunnar \& Stone, 1984).

Social referencing has been criticized as actually reflecting the more simple mechanisms of affect imitation or mood modification (Walden \& Ogan, 1988). Mood modification involves an expression by the referee that actually changes the mood of the referrer (presumably through some sort of emotion contagion process), thereby changing the behavior of the referrer toward any object or situation in the environment rather than just toward the referent, or object to which the expression is directed. However, previous research has provided evidence that social referencing and mood modification are separate phenomena. Stenberg and Hagekull (1997) had mothers use particular signals in response to a novel toy. Their results indicated that infant behavior changed toward the toy, while the overall mood of the infant, as indicated by measures of facial affect, did not. In another study, Hornik, Risenhoover, and Gunnar (1987) presented infants with a novel toy, to which the mothers responded negatively. After this presentation, the infants were allowed several minutes of free play with other toys that were in the room. The observers found that the infants played normally with the other toys while avoiding the stimulus toy, indicating that their overall mood had not changed and that they understood that the message was specific to the stimulus toy. No differences in facial affect were noted, giving more credence to the assertion that social referencing, and not mood 
modification, had indeed taken place.

Over the years, there has also been discussion regarding whether social referencing is biologically prewired (Campos, 1983). More recently, however, Gewirtz and Pelaez-Nogueras (1992) have provided evidence to indicate that social referencing can also be conceptualized as a product of operant learning. In their study, infants were presented with an ambiguous stimulus and then looked to their mothers. Instead of reacting with a positive or negative emotional expression, however, the mothers presented their infants with one of two arbitrary behavior patterns, neither of which inherently suggested a particular emotion (e.g., placing a closed fist on their forehead). When the infant reacted to the expression and turned to the stimulus, they received either negative reinforcement (e.g., an aversive sound paired with the stimulus) or positive reinforcement (e.g., pleasant music paired with the stimulus). In time, the infants learned to discriminate the two maternal behaviors and reacted to the stimuli appropriately. According to Gewirtz and Pelaez-Nogueras, this same process occurs with emotional expressions in the natural environment; in time, the infant learns the consequences of reacting in certain ways to particular facial expressions.

Rather than taking an either/or, nature/nurture stance with respect to the sources of emergence of social referencing behavior, in the present study, social referencing was conceptualized as a dynamic behavior pattern, one that is influenced by various related factors and task demands (Eckerman, 1993). The objective in a dynamical analysis is to determine transition points in the development of this new behavior, during which increased variability in related variables should be observed (Siegler, 1996; Thelen \& Smith, 1994). While dynamical analyses have most often been used to study motor 
development, such as the onset of walking, the method has also been applied to the domain of social cognition, most specifically in the area of communicative action (Fogel \& Thelen, 1987), and is continuing to be applied in this area (Lewis, Lamey, \& Douglas, 1999). These authors reconceptualized the developmental processes involved in crying, smiling, and pointing to show that the reorganization of such behaviors during the first year of life provides the infant with more sophisticated communicative abilities.

A dynamical analysis therefore involves understanding a pattern of changes over time in a particular variable (called a collective variable) that is well defined and observable (Thelen \& Smith, 1994). Dynamical analyses can be conducted through multiple methods, including various quantitative mathematical and statistical procedures (Barton, 1994; van Geert, 1994). Key conceptual features of dynamic systems theory, however, entail methodological approaches that are more qualitative in nature (Haynes, Blaine, \& Meyer, 1995; van Geert, 1994), and hence provide a starting place for thinking in new ways about investigating behavioral development in a domain like social referencing. First, the idea that continuous changes in certain components of a system can lead to sudden state changes provides us with a mechanism for transitions to novel forms (or stages) (Barton, 1994; Rosales-Ruiz \& Baer, 1996). This suggests the need for a large number of observations of the system just prior to the time of change and a search for high levels of behavioral variability in the system at the time of change (Siegler, 1996).

Second, dynamical systems are seen as self-organizing in that stable, new structures or patterns emerge in open systems (ones that exchange energy) without necessarily being specified by external, environmental constraints. An example of self- 
organization comes from the footfall pattern, or gait, of a horse, as increases in the energy being expended toward forward locomotion result in dramatic changes in the form of the locomotion. These constraints on possible changes in locomotion form are in large part determined by the anatomical structure of the horse (Thelen, 1995). Dynamical systems therefore involve both stability and flexibility, and are susceptible to restructuring with small perturbations in various aspects of the system. Thus, strategies for examining dynamic systems should focus on the conditions that invoke transitions and variability at the local level. In other words, examination of task demands and their influence on performance are critical (Eckerman, 1993; Kelso, 1995; Siegler, 1996; van Geert, 1994).

In this study, the goal was to examine changes in social referencing behavior, which is the collective variable. In addition, this study investigated several factors that might be related to the development of referencing behavior, including joint attention, language, temperament, maternal sensitivity, and several aspects of the home environment. Furthermore, particular task demands, such as degree of uncertainty, degree of ambiguity, and context, have already been identified and were used in this study to manipulate referencing behavior so that it could be closely examined. Justification for these related factors and task demands follows.

\section{Related Factors}

$\underline{\text { Joint visual attention and pointing. Joint visual attention and comprehension of }}$ pointing are two social cognitive behaviors that also develop toward the end of the infancy period (Leung \& Rheingold, 1981; Morissette, Ricard, \& Decarie, 1995). Joint visual attention involves the ability to follow another person's visual line of regard to focus on the same stimulus (Moore \& Dunham, 1995). Comprehension of pointing 
involves the ability to follow the invisible line from the pointing finger to a stimulus in order to focus on that stimulus. Joint attention and point comprehension involve the infant's developing ability to use eye gaze, facial expressions, and the actions of others to infer "referential intent," the appreciation that attention can be directed at a particular object (Repacholi \& Gopnik, 1997; Repacholi, 1998). Both pointing and joint visual attention therefore incorporate an object or an event into the communication between two people, features of an interaction that overlap with those involved in social referencing.

Language. Language is also developing during the same period of time as social referencing behavior emerges. As they begin to acquire a vocabulary, infants begin to understand the referential intent of language, meaning that they can appreciate the fact that language and speech are directed at a particular object (Baldwin \& Moses, 1994; Nelson, 1999). This is crucial to social referencing, as mothers often use vocal cues to guide the infant's behavior toward the ambiguous situation. Studies have also shown that referential behavior is utilized for the important task of word learning, in that infants learn the names of objects by attending to the same object as another person and associating the corresponding word with that object (Baldwin, 1993; Messer, 1978; Moore, Angelopoulos, \& Bennett, 1999).

Temperament. Infants classified as temperamentally easy use information provided during a social referencing interaction to a greater extent than those classified as difficult (Feinman \& Lewis, 1983). The present study assessed the behaviors that have been identified as consistent with the temperament categories easy and difficult. Generally, infants who are high in activity level, smiling and laughter, soothability, and duration of orienting and low in distress to limitations and distress and latency to 
approach sudden or novel stimuli are considered easy, while infants with the opposite tendencies are considered difficult.

Maternal sensitivity and the home environment. Dickstein et al. (1984) examined the relation between security of attachment and maternal referencing and found that resistant babies reference the most, avoidant do so the least, with secure babies in the middle. Maternal sensitivity is a factor often associated with attachment classification and is usually defined as the responsiveness of the mother to her infants' signals and needs (de Wolff \& van IJzendoorn, 1997). Explorations of this factor have found that it is indeed strongly related to attachment (de Wolff \& van IJzendoorn, 1997; Pederson, Gleason, Moran, \& Bento, 1998). Infants with mothers who have low ratings of maternal sensitivity, who are generally classified as insecure or resistant, may reference more due to the fact that they are generally more anxious and uncertain (Ainsworth \& Wittig, 1969, as cited in Dickstein et al., 1984). Experimental manipulations of maternal sensitive responsiveness have been shown to impact infant sociability, self-soothing behavior, and exploration (van den Boom, 1994). Thus, maternal sensitivity may play a role in social referencing in that infants are more likely to reference their mother if they have learned that they will consistently receive a response from their mother. The present study assessed maternal sensitivity as a variable that leads to individual differences in the onset of social referencing. In addition, other factors related to the home environment that may be related to the novelty aspects of social referencing, such as exposure to situations outside the home and the number of opportunities for multiple experiences and interactions with objects outside the home, were also assessed. 


\section{$\underline{\text { Task Demands }}$}

The present study manipulated various factors that influence social referencing behavior as a means of eliciting and measuring variability in referencing behavior. These factors include ambiguity of the stimulus or uncertainty of the infant and the context of the social referencing paradigm.

Ambiguity/uncertainty. It has been found that the degree of the child's uncertainty and the ambiguity of the stimulus are related to social referencing (Zarbatany \& Lamb, 1985). Uncertainty can be defined as the degree to which one is unsure of how to react toward a particular situation, as indicated by quizzical or concerned facial expressions (Feinman, 1982; Feinman et al., 1992). To achieve this state of uncertainty, ambiguity of the stimulus is especially important. However, while Feinman (1982) theorized that uncertainty was a necessary condition for referencing behavior, Hornik and Gunnar (1988) found that uncertainty may not be necessary for social referencing. In this study, infants were presented with a live rabbit and were classified as either wary or bold on the basis of their initial reactions toward the rabbit. The results of the study revealed that wary and bold infants referenced equally often; thus, even those infants who appeared unhesitant regarding the new stimulus looked to their mothers for information regarding the rabbit. Therefore, uncertainty may not be a necessary precursor for social referencing behavior, although most studies have found more referencing in uncertain infants. In the present study, three types of potentially ambiguous stimuli were used: strangers, loud noises, and novel objects.

Context. Context has been shown to produce differences in referencing in that infants in more familiar settings look to the adult for a signal more quickly and seek 
closer proximity than do infants in unfamiliar settings (Walden \& Baxter, 1989), although this is the reverse of what these authors hoped to find. Therefore, several social referencing assessments were conducted in the home in addition to the laboratory assessments to measure differences in context in the present study.

\section{The Present Study}

This study was an intensive, short-term longitudinal study whereby social referencing behavior was closely examined every week for a period of four months, beginning when the infants were 7 months old, one full month before the earliest onset has been observed. Social referencing was assessed with a variety of tasks on a weekly basis. The infant was also assessed every two weeks on language and joint visual attention and comprehension of pointing. Temperament, aspects of the home environment, and maternal sensitivity were assessed at the beginning, middle, and end of the study, and context was assessed on a regular basis throughout the course of the study. Because a dynamical theory of developmental change was assumed, no independent or dependent variables are identified. Instead, numerous close observations and assessments were obtained over a large period of time, spanning the period of change in social referencing. The purpose of this format was to observe the onset of social referencing, to assess variability in social referencing, and to track the development of other related behaviors in the hopes of determining the particular skills that come together to promote social referencing behavior in the infant.

\section{Method}

\section{$\underline{\text { Participants }}$}

The participants in this study were five healthy infants, three males and two 
females, with a mean age of 7 months and 5 days at the beginning of the study (range: 6 months, 29 days to 7 months, 21 days). One additional infant participated in three assessments before dropping out of the study; this infant's data is not included in the present report. Infants were recruited from the Morgantown area. One infant was recruited through a personal contact, while the remaining four were recruited through information obtained in the local birth records. Approximately 25 mothers were called to recruit these 4 infants. Reflecting the demographics of the area, the participants were Caucasian and primarily middle-class. All five infants came from intact families; two of the infants were only children, two had one older sibling, and one had two older siblings. Of the mothers, one had completed only high school, two had completed some college, one had graduated from college, and one had graduated from law school. Four of the mothers were homemakers while one worked full time. Of the fathers, one had completed only high school, one had completed some college, one had graduated from college, one was about to graduate from dentistry school, and one had graduated from law school. All of the fathers worked full time outside of the home. See Appendix A for a copy of the demographics questionnaire, from which this information was obtained. Assessments took place both in the homes and in a laboratory playroom on a university campus and were conducted on a weekly basis for four months for each infant. Participants were paid twenty-five dollars at the midpoint of the study, and an additional fifty dollars at the end of the study for a total of seventy-five dollars.

\section{$\underline{\text { Instruments and Materials }}$}

Language. The Reynell Language Comprehension Scale for Infants (RDLS;

Reynell \& Huntley, 1985), an experimenter administered scale, was used to measure 
infant language comprehension. To administer this scale, the experimenter laid out sets of objects. After getting the child's attention, the experimenter would ask a question such as, "Where is the ball?" and wait for the child to respond. A point, reach, or direct look to the object was scored as a correct response. The scale is arranged sequentially so that easier and more familiar objects are presented first, while more difficult objects that might require more action on the part of the child follow. Internal reliability for the Reynell is quite high, ranging from .45 to .97 and good concurrent validity has been shown to other measures of early child language, such as the Wechsler Pre-school and Primary Scale of Intelligence subscales and the Illinois Test of Psycholinguistic Ability (Reynell \& Huntley, 1985). Raw scores equaled the total number of objects comprehended. In addition, the number of items comprehended by the infant was converted to a standard score at 11 months using the lowest age range (12 months, 0 days) available in the technical manual.

The MacArthur Communicative Development Inventory: Infants (MCDI; Fenson, Dale, Reznick, Thal, Bates, Hartung, Pethick, \& Reilly, 1993), a parent report measure of early child language, was also used. The MCDI instructed parents to report their infant's understanding and production of various words and phrases, as well as various social gestures in which the infants may engage. The internal consistency of the MCDI: Infants shows coefficients ranging from .39 on the gestures scale to .96 on the vocabulary scale and test-retest reliability ranges from .6 to .9 for both the vocabulary and gestures scales (Fenson, et al., 1993). Studies have also shown high concurrent validity on the toddler form to other early language measures such as the Expressive One Word Picture Vocabulary Test and the Type-Token Ratio. In addition, studies with the infant form 
indicate that the scale measures the same language skills as those obtained in the laboratory (Fenson, et al., 1993). A total score was derived from the MCDI by summing all positive responses to the following subscales: first signs of understanding, phrases, starting to talk, vocabulary checklist, first communicative gestures, games and routines, actions with objects, pretending to be a parent, and imitating other adult actions. In addition, percentile scores at the beginning, middle, and end were obtained for the vocabulary checklist.

Maternal sensitivity and the home environment. The Home Observation for the Measurement of the Environment (HOME; Caldwell \& Bradley, 1989) was used to measure aspects of maternal sensitivity and the home environment. This semi-structured interview, in which the experimenter observed the home environment and questioned the parents when needed, is designed to assess several parental factors, as well as the organization of the physical environment. The following factors are assessed by the HOME: responsivity of the mother, use of punishment, organization of the environment, availability of appropriate play materials, maternal involvement, and variety in daily stimulation provided to the child. Internal consistency for the HOME has been reported to be as high as .89 , while studies that have compared the measure to socioeconomic variables have found sufficient concurrent validity as well (Elardo, Bradley, \& Caldwell, 1977). The measures derived from this measure are the scores on the subscales previously mentioned. Scores were based on answers to yes/no questions and are the sum of all "yes" answers divided by the number of items per scale.

Temperament. The Infant Behavior Questionnaire (IBQ; Rothbart, 1981) was used to assess infant temperament. This parent report scale assessed infant behavior 
under a variety of everyday situations and provided an indication of whether the infant can be classified as easy or difficult. The questionnaire asks mothers to rate, on a Likert scales of 1 to 7 , how often their infant behaves in particular fashions when engaging in the following daily routines ( 1 equals very infrequently and 7 equals very frequently): feeding, sleeping, bathing and dressing, play, daily activities, and soothing techniques. Internal reliability for the IBQ has been shown to be quite high, ranging from .67 to .84 on the various dimensions (Goldsmith \& Rothbart, 1991). Studies have also found sufficient convergence among the IBQ and other measures of temperament to allow for adequate validity (Goldsmith \& Rothbart, 1991). The measures derived from this scale are the infant's scores on each of the following dimensions: activity level, smiling and laughter, distress and latency to approach sudden or novel stimuli, distress to limitations, soothability, and duration of orienting. Scores are obtained by summing all responses given in a particular dimension and then dividing by the total number of items in that dimension. Only the distress and latency to approach sudden or novel stimuli and smiling and laughter subscales were used in the present study.

$\underline{\text { Social referencing. }}$ Most assessments took place in a large laboratory playroom that was equipped with a one-way mirror. The rest of the assessments took place in the infants' homes. Home assessments were set up as closely as possible to the laboratory set-up. All social referencing assessments were videotaped. Furniture in the laboratory observation room included a highchair, table, and chair. Materials used for the social referencing assessments included a sound effects CD to play loud and unfamiliar noises, a Slinky (with which the infant played during the noise paradigm), a puppet theatre created out of a project display board, and several novel objects created by the 
experimenter out of various craft materials.

Joint visual attention and pointing. All joint attention assessments took place in the same laboratory playroom as the social referencing assessments and were videotaped. The materials for the assessment of joint visual attention and pointing included a baby seat for the infant, a cloth sheet for the mother to sit on, four posts of equal size (approximately 8 inches in height) and four identical "aliens" made of bath tissue rolls and styrofoam balls (approximately 6 inches in height).

\section{$\underline{\text { Procedures }}$}

Language. The MCDI was completed by the mother every two weeks throughout the course of the study. The experimenter gave the mother the scale the week before the session it was due and instructed the mother to complete the form as close to the next session as possible. The Reynell was administered by the experimenter at the beginning, middle, and end of the study.

Maternal sensitivity and the home environment. The experimenter completed the HOME Inventory at the first, middle, and last home visits of the study. It was completed at the end of each visit in the presence of the infant and mother.

Temperament. The mother completed the IBQ at the beginning, middle, and end of the study. The experimenter gave the mother the scale the week before it was due and instructed the mother to complete the form as close to the next session as possible.

$\underline{\text { Social referencing. Social referencing behavior was assessed once a week for }}$ every infant during the four-month period of assessment through the use of three social referencing tasks: stranger approach, noise, and puppet show. Each assessment involved two of the three tasks, and two trials were given for each task. These tasks varied in 
combination for each visit. New stimuli were used for each repeated assessment.

For these assessments, the mother and infant entered the room together after the experimenter had entered and hidden herself, with the exception of the stranger paradigm, for which the experimenter remained outside the room. The mother settled the infant in the high chair and took her seat and the assessment began when both were comfortable. Home assessments were conducted in the same manner as laboratory assessments. Time between trials varied depending on the mood and activity of the infant and mother.

The mothers were instructed to react toward each stimulus as they would naturally react to a new object or situation in the infant's environment. No effort was made to experimentally control for emotional content of the reaction.

The stranger approach involved only the use of the highchair and chair. The high chair faced the one-way mirror, with the door to the room on the infant's right. The chair for the mother was placed slightly to the front of the high chair and faced the door so that the infant had easy visual access to the mother. When the mother and infant were comfortable, a stranger entered the room ( 3 seconds), spoke to the mother (5 seconds), spoke to the infant (5 seconds), approached the infant ( 3 seconds), and, finally, picked the infant up (20 seconds). Most strangers spoke in "baby talk" to the infants and all were instructed to act in a friendly manner and attempt to cuddle the infant briefly before handing him or her to the mother. The stranger then handed the infant to the mother and left the room. For approximately $36 \%$ of the sessions, when both mother and infant were settled again, a new stranger repeated the episode. For the remaining sessions, only one trial of this paradigm was carried out because only one stranger was available.

The noise paradigm involved the use of the high chair, chair, Slinky, CD player, 
$\mathrm{CD}$, and puppet show. The highchair and chair were placed in the same position as for the stranger approach, with the Slinky placed on the tray of the highchair. The puppet theatre was placed in the corner to the infant's right and hid the experimenter and CD player. The infant and mother were seated and the mother engaged the child in playing with the Slinky. When both were comfortable, an experimenter, who was hidden behind the puppet theatre, played a sound effect for a period of 10-20 seconds (See Appendix B for a list of sound effects and decibel levels). After approximately 15 seconds of silence, the same sound was played again. The experimenter then waited for a minute or two, depending on the behavior of the infant, and repeated the procedure with a different sound.

The puppet show paradigm involved the use of the highchair, chair, table, puppet theatre, and several novel objects. The puppet theatre was placed on the tabletop, and the infant's highchair was parallel to the table and facing right so that the infant was directly facing the one-way mirror. The mother's chair was perpendicular to the infant's highchair so that the mother was directly facing the puppet show, which allowed for easy visual access of both the mother and the novel object by the infant. When the mother and infant were comfortable, the experimenter behind the puppet theatre pushed one of the novel objects through the opening in the theatre, toward the infant. The object was left in the infant's presence for approximately 30 seconds before being taken back. After a period of one to two minutes, depending on the behavior of the infant, the procedure was repeated with a second object.

The primary experimenter coded all social referencing data. The experimenter coded each infant's initial affect as either positive, negative, or neutral, according to the 
criteria presented in Appendix C. The number of looks to the mother, after regarding the stimulus, were counted for each trial. The derived measure was the number of looks to the mother after regarding the stimulus for those trials in which the initial affect was neutral (approximately 95\%). In the noise paradigm, these looks were broken down to determine how many occurred the first time the noise was played and how many occurred the second time the same noise was played. In the stranger approach, the looks were broken down to determine the number of looks to the mother before the stranger picked the infant up as opposed to the number of looks after the pickup.

$\underline{\text { Joint visual attention and pointing. Joint visual attention and comprehension of }}$ pointing were assessed in the laboratory every two weeks throughout the course of the study. Each assessment consisted of one trial of each of three tasks: look with only eyes, look with eyes and head, and look with eyes and head while pointing. The order of tasks varied among assessments; the mother performed all tasks.

The infant seat was placed on the far side of the room, directly across from and facing the one-way mirror. The mother was seated on a cloth sheet directly across from the infant, approximately five feet away, directly in front of and facing away from the mirror. The posts were set up in a straight line exactly halfway between the infant and mother. Two posts were on either side of the imaginary line between the mother and infant, with the inside two being approximately one foot from that line and the outer two being approximately three feet from that line. One alien was placed on each post at the start of each session.

Mother and infant entered the playroom together and the mother placed the infant in the baby seat before taking her seat on the cloth sheet. The mothers were instructed to 
continue each task for approximately ten seconds, or until the infant looked at the correct alien, before moving to the next task.

For the look with only eyes task, the mother was instructed to get her infant's attention and look at one of the four aliens, designated by the experimenter, by moving her eyes only, while keeping her head facing straight ahead. For the looking with eyes and head task, the mother was instructed to get her infant's attention and to look at the alien by turning her eyes and head towards it. Last, in the pointing task, the mother behaved as in the looking with eyes and head task, but also pointed to the designated alien.

The primary experimenter coded each infant's behavior during both the pointing and joint visual attention conditions (see Appendix D). Infants were assessed to determine whether they understood the referential aspect of the gestures their mothers were presenting to them. Infant behavior was recorded as one of the following for each task: (1) the infant keeps looking at the mother, looks at the opposite side of what is indicated, or looks to both sides; (2) the infant looks only at the pointing hand; (3) the infant looks on the side indicated, but does not look at the specific target; (4) the infant looks at the wrong target on the correct side, or looks at the wrong target on the correct side and then looks at the correct target; (5) the infant looks directly at the correct target. Results Infants' language comprehension scores, as measured by the MCDI and RDLS are presented in Table 1. The MCDI scores presented were percentile scores and indicated a fair amount of variability between and within infants. It should be noted that the extremely low scores of Infant 3 were likely a result of the mother underestimating 
her child's abilities, as this infant scored within the ranges of the others on the RDLS. The RDLS scores presented were raw scores, or the number of objects comprehended by the infant, and indicated less variability than the MCDI. Infants' standard scores on the RDLS at 11 months of age ranged from .9 to 2.3 , meaning that these infants' scores ranged from .9 to 2.3 standard deviations above the mean.

As shown in Figure 1a., Infants 1 and 5 displayed dramatic increases in their raw scores on the MCDI, while Infant 2 and 3 showed minor increases and infant 4 showed moderate increases. As for communicative gestures, presented in Figure 1b., Infants 1, 2, 4, and 5 showed steady increases, while Infant 3 showed very minor change in the positive direction.

As seen in Table 2, all five mothers scored quite high on all dimensions of the HOME. On the maternal responsivity dimension, most mothers scored $90 \%$, while one scored $81 \%$ at the last two times of measurement and $90 \%$ at the first. On the dimension of maternal involvement, the scores ranged from $66 \%$ to $100 \%$, with several mothers showing slight variability across time. Scores on the avoidance of restriction and punishment dimension ranged from $75 \%$ to $88 \%$ and mothers showed relative stability across time within this dimension. On the dimension relating to the organization of the environment, all mothers scored $100 \%$ at all times, with the exception of one mother who scored $83 \%$ at the second time of measurement. Scores were very variable on the play materials dimension, ranging from $33 \%$ to $88 \%$; mothers of Infants 1, 3, and 5 showed some stability over time, while mothers of Infants 2 and 4 had scores that varied across time. All mothers scored $60 \%$ on the variety in daily stimulation dimension at all times of measurement, with the exception of one mother, who scored $80 \%$ at the first time of 
measurement.

The temperament data, presented in Table 3, indicate that all five infants had relatively low levels of distress and latency to approach novel stimuli at all three times of measurement, with scores ranging from 1.13 to 2.93 out of a possible score of 7 . All infants also scored relatively high on the dimension of smiling and laughter at all three times of measurement, with scores ranging from 2.13 to 6.73 out of a possible score of 7 .

All five infants were engaging in referencing behavior from the beginning of the study, and as can be seen in Figure 2, this referencing behavior showed great variability. For all five infants, the noise paradigm elicited the most number of looks, while the puppet show paradigm elicited few looks, with the stranger paradigm falling in the middle. A closer look at the stranger paradigm, presented in Figure 3, reveals that all five infants showed more looking to the mother after being picked up by the stranger than before the pick-up occurred. Data from the noise paradigm, presented in Figure 4, indicate that all five infants had a tendency to look more to the mother the first time the noise was played than they did the second time the same noise was played. Finally, as presented in Figure 5, the context of the social referencing paradigm appeared to have an effect on the amount of referencing in which the infants engaged. All five infants engaged in more referencing behavior in the laboratory than in the home assessments.

The joint attention data, presented in Figure 6, reveal that all five infants were able to engage in all three aspects of joint visual attention by the end of the study. The results show that the ability to follow eye gaze, head direction, and the pointing finger in combination tended to develop first. Infants 2, 3, 4, and 5 exhibited the ability to follow the pointing hand and the head turn by about weeks three to five, or ages 7.5 to 8 months. 
Infant 1 did not show these skills until around week 15, or age 10.5 months. However it should be noted that this infant is missing data on the prior two assessments due to excessive fussiness and may have exhibited this ability earlier had the infant been tested. The ability to follow the mothers' eye gaze plus head turns towards the target object developed closely behind the ability to follow the eye gaze, head turn, and the pointing finger for all five infants. The ability to follow eye gaze only, however, developed somewhat later; Infants 2, 3, 4, and 5 appear to have developed this ability around week 13, or 10 months of age, while Infant 1 did not achieve this ability until around week 17 , or 11 months of age.

Figures 7 through 11 represent all of the data for each infant. It can be noted that Infant 1, presented in Figure 7, showed sharp increases in language scores and the number of communicative gestures exhibited at about the same time. That was also about the same time that this infant achieved comprehension of eye gaze, head turn, and pointing in the joint attention task. There was no clear relation between social referencing behavior and any other variables.

The data for Infant 2, presented in Figure 8, indicate that, while increases in the language score were only gradual, the time at which they began to increase was accompanied also by an increase in communicative gestures. Joint attention and comprehension of eye gaze, head turn, and pointing, however, were acquired prior to this time with this particular infant. Again, there was no apparent relation between social referencing and other variables.

There is very little increase in the language scores for Infant 3, as presented in Figure 9, and neither is there a particularly sharp increase in communicative gestures. 
Joint attention and comprehension of eye gaze, head turn, and pointing are acquired near the beginning of the study and their onset does not appear to coincide with a period of increasing language or gesture development. There is also no relation between social referencing and these other factors in this infant.

Infant 4, as seen in Figure 10, showed a steady increase in language development beginning around week 11 of the study, which is in the midst of an ongoing increase in communicative gestures. Again, however, joint attention and comprehension of eye gaze, head turn, and pointing are acquired prior to this period of change. In this infant, there also appears to be a relation between social referencing and the development of language and communicative gestures; here, there was an increase in referencing behavior at the same time that both language and communicative gestures were increasing.

Finally, Infant 5, presented in Figure 11, showed a sharp increase in language scores beginning around week 11 of the study, at a time when the number of communicative gestures is leveling off. Joint attention and comprehension of pointing are also acquired prior to this change in infant five. Here again, there was no noted relation between social referencing and any other factors.

\section{Discussion}

While the purpose of this study was to examine the onset of social referencing, all five infants were looking to their mothers from the very beginning of the study, at seven months of age. As the earliest report of such behavior in the literature is around ten months of age, this, in itself, is an interesting, although unexpected finding. However, while variability and change in referencing behavior were still observed, because all five 
infants were referencing at the beginning of the study, we were unable to examine the factors that might be associated with the onset of the behavior.

There are several possible reasons for the fact that we witnessed referencing behavior so early. For one, our definition of social referencing may have been more liberal than those used in other studies. For the purposes of this study, social referencing was defined as looking to the mother after regarding the stimulus with a wary expression, as defined by some authors (Camras \& Sachs, 1991; Dickstein \& Parke, 1988; Dickstein, et al., 1984). Others, however, require that there be other changes in the infant's behavior for referencing to occur (Feinman, 1982; Gunnar \& Stone, 1984; Klinnert, et al., 1986). Second, the present study used a noise task, whereby the infants were exposed to loud noises, a paradigm that has not been used in published studies of social referencing. It was this paradigm in which the most looks were observed and it could be that the noise task is a more effective means of eliciting referencing behavior than the more traditional paradigms.

The joint visual attention data indicate that comprehension of eye gaze, head turn, and pointing generally occurs before the infant can follow a visual line of regard only. Most infants in the present study were able to comprehend eye gaze, head turn, and pointing by eight months of age, whereby they followed their mothers' pointing finger directly to the target object. The ability to follow the mothers' eye gazes only and her looks with her eyes and head tended to co-emerge around nine months of age. The variability and erratic behavior noted in this data are due to infant distress and are not considered to be lapses in understanding. This stands in contrast to the findings of Leung and Rheingold (1981) who found that many 10.5- month-olds could not follow the 
pointing finger to focus on a particular object and to Moore and Corkum (1998) who found that infants could not follow eye gaze alone until 18 months of age (although see Danziger, Kinstone, \& Rafal, 1998, for a report of very early ability in this area). Leung and Rheingold also found that infants began pointing at objects when they were approximately 12.5 months old. None of the infants in this study pointed at objects in the joint visual attention assessments, indicating that by 11 months of age, infants may not quite have this ability.

The RDLS scores of language comprehension at 11 months of age showed that all five infants scored above the mean for 12-month-olds, indicating that their language comprehension is likely somewhat advanced. This, too, may account for the early social referencing if, indeed, language is related to the development of this phenomenon. Therefore, future studies should attempt to use infants with low and normal language scores so that the effects of language could be assessed.

While maternal sensitivity was assessed through the HOME in the present study, there were no differences between the mothers. Thus, we could not examine the effect of differential levels of sensitivity on social referencing behavior. Future studies should take care to incorporate a group of low sensitive mothers so that such effects can be examined. Additionally, future studies should use different measures of this behavior, including direct observation of mother-infant interactions, due to the low ceiling of the HOME.

Because all five infants scored rather low on the temperament dimension of distress and latency to approach novel stimuli and rather high on the dimension of smiling and laughter, they exhibited characteristics of an easy temperament. Also, these 
scores indicate that the infants are likely not shy or anxious, and would therefore be more likely to easily reference (Feinman \& Lewis, 1983). This may also be a reason that social referencing was observed so early in the present study; thus, future studies should seek infants who are more temperamentally difficult, especially on these two particular dimensions.

In the noise task of social referencing, the data show that in most cases infants looked to their mother more the first time the noise was played than they did the second time the same noise was played. This might indicate that, not only were these infants looking to their mothers at an earlier age than expected, but that they were also able to use the information received from their mothers, hence they did not need to look as much, if at all, the second time the noise was played.

In the stranger task of social referencing, it was noted that nearly all looking behavior occurred after the infant was picked up by the stranger, rather than before. This may indicate that infants do engage in more referencing behavior when in a more unfamiliar situation, as being picked up by a stranger is much more stressful and unfamiliar to an infant than merely being in the stranger's presence.

The most notable effect is the difference in referencing behavior noted between the laboratory setting and the home setting, indicating that context may play a role in social referencing. All five infants engaged in more looking behavior when in the laboratory than in the home, perhaps due to the fact that the laboratory is unfamiliar, thereby increasing the infants' uncertainty and likelihood of referencing. $\underline{\text { Future Directions }}$

Future studies in this area should begin with younger infants and perhaps extend 
the study to follow infants past their first birthdays in order to examine social referencing from its emergence to a point of stability. This study was unable to detect the emergence of the behavior as all five 7-month-old infants were referencing from the beginning. Also, the behavior continued to be variable within each infant over the course of the study, although this could be due to variability in the stimuli. Future studies, therefore, should also seek to test the ambiguity of the stimuli used.

Research has also shown that infants are more responsive to vocal expressions than they are to facial emotions (Mumme et al., 1996). In related research, Camras and Sachs (1991) have found that caretaker expressiveness is related to social referencing in that infants with more emotionally expressive caretakers are more likely to engage in social referencing and are more responsive to the messages they receive. The present study made no effort to control or examine either of these factors, both of which could potentially have effects. Thus, future studies should examine the differential effects of vocal and facial expressions and the effect of caretaker expressiveness on the emergence of social referencing.

In his review of social referencing in infancy, Saul Feinman (1982) stated that infants are selective in their referencing, meaning that infants would only reference familiar adults, most notably their mothers. Since this claim, several studies have been undertaken to verify the statement. In all, studies have shown that, while selective, referencing behavior is not exclusively directed at the mother. Infants show no significant differences in referencing mothers versus fathers in the presence of both (Hirshberg \& Svejda, 1990). Similarly, when the parents were tested individually with the infant, infants still referenced mothers and fathers equally (Dickstein \& Parke, 1988). 
Klinnert, Emde, Butterfield and Campos (1986) found that infants will reference familiar strangers in the presence of the mother, while Zarbatany and Lamb's (1985) study revealed the opposite; infants only referenced the mother, even when the stranger was giving emotional signals as well. However, later studies revealed that infants will reference familiar adults, such as daycare workers, even when the mother is not present (Camras \& Sachs, 1991). Recently, Walden and colleagues (1999) have shown that older infants will reference strangers instead of parents in certain circumstances, indicating that they may consider expertise and credibility when deciding whom to look at. Taken together, these studies indicate that referencing is indeed selective, although not to the extent that was once thought. However, a closer examination of these studies indicates that there may be a developmental progression in referencing parents and referencing others. Those studies that looked at referencing to the parents dealt primarily with younger infants, with the mean age being 11.5 months. Those studies that sought to identify referencing behavior toward strangers generally used older infants, with the mean age being 13.5 months. Therefore, infants may reference parents and other close attachment figures before they will reference strangers and familiar adults. Because this study would not be looking at infants as old as those that have been shown to look at strangers, we did not include this as a measure. However, on several occasions, infants in the present study did look to strangers and the experimenter during the social referencing assessments, indicating that looking to strangers may also occur earlier than studies have shown. Therefore, future studies should include this manipulation to determine the point at which infants will reference strangers.

There has already been a fair amount of research relating the early social 
cognitive behavior of social referencing to aspects of the mother-infant relationship, such as attachment and sensitivity. However, there is less work relating these types of factors to the more "cognitive" social cognitive skill of joint attention. The results from this study showed an emerging pattern of development in joint attention skills, which should be further examined in relations to such factors as maternal sensitivity and temperament.

Finally, while the method of investigation in the present study involved visual examination of graphical depictions of social cognitive behaviors at the end of the first year, additional descriptive analyses based on trajectories over time should be performed (Lewis, 2000). In particular, determination of the type of path of developmental change, whether uniform, steady-state, decelerating, rising and decaying, or involving a variable growth rate, may be possible using various mathematical modeling techniques (van Geert, 1994, 2000). 


\section{References}

Ainsworth, M.D.S., \& Wittig, B.A. (1969). Attachment and exploratory behavior of one-year-olds in a strange situation. In B.M. Foss (Ed.), Determinants of infant behavior IV. London: Methuen.

Baldwin, D.A. (1993). Early referential understanding: Infants' ability to recognize referential acts for what they are. Developmental Psychology, 29, 832-843.

Baldwin, D.A., \& Moses, L.J. (1994). Early understanding of referential intent and attentional focus: Evidence from language and emotion. In C. Lewis \& P. Mitchell (Eds.), Children's early understanding of mind: Origins and development (pp. 133-156). Hillsdale, NJ: Erlbaum.

Baldwin, D.A., \& Moses L.J. (1996). The ontogeny of social information gathering. Child Development, 67, 1915-1939.

Barton, S. (1994). Chaos, self-organization, and psychology. American Psychologist, 49, 5-14.

Caldwell, B., \& Bradley, R. (1989). Home observation for the measurement of the environment. New York: Dorsey.

Campos, J.J. (1983). The importance of affective communication in social referencing: A commentary on Feinman. Merrill-Palmer Quarterly, 29, 83-87.

Camras, L.A., \& Sachs, V.B. (1991). Social referencing and caretaker expressive behavior in a day care setting. Infant Behavior and Development, 14, 27-36.

Danziger, S., Kingstone, A., \& Rafal, R.D. (1998). Orienting to extinguished signals in hemispatial neglect. Psychological Science, 9, 119-123.

Desrochers, S., Ricard, M., Decarie, T.G., \& Allard, L. (1994). Developmental 
synchrony between social referencing and Piagetian sensorimotor causality. Infant Behavior and Development, 17, 303-309.

de Wolff, M.S., \& van IJzendoorn, M.H. (1997). Sensitivity and attachment: A meta-analysis on parental antecedents of infant attachment. Child Development, 68, 571591.

Dickstein, S., \& Parke, R.D. (1988). Social referencing in infancy: A glance at fathers and marriage. Child Development, 59, 506-511.

Dickstein, S., Thompson, R.A., Estes, D., Malkin, C., \& Lamb, M.E. (1984). Social referencing and the security of attachment. Infant Behavior and Development, 7, 507-516.

Eckerman, C. (1993). Toddler's Achievement of Coordinated Action with Conspecifics: A Dynamic Systems Perspective. In L.B. Smith \& E. Thelen (Eds.), $\underline{A}$ dynamic systems approach to development: Applications (pp. 333-357). Cambridge, MA: MIT Press.

Elardo, R., Bradley, B., \& Caldwell, B.M. (1977). A longitudinal study of the relation of infants' home environments to language development at age three. $\underline{\text { Child }}$ Development, 48, 595-603.

Feinman, S. (1982). Social referencing in infancy. Merrill-Palmer Quarterly, 28, 445-470.

Feinman, S., \& Lewis, M. (1983). Social referencing at ten months: A secondorder effect of infants' responses to strangers. Child Development, 54, 878-887.

Feinman, S., Roberts, D., Hsieh, K., Sawyer, D., \& Swanson, D. (1992). A critical review of social referencing in infancy. In S. Feinman (Ed.), Social referencing 
and the social construction of reality in infancy (pp. 15-54). New York: Plenum Press.

Fenson, L., Dale, P.S., Reznick, J.S., Thal, D., Bates, E., Hartung, J.P., Pethick, S., \& Reilly, J.S. (1993). MacArthur Communicative Development Inventory. San Diego, CA: Singular Publishing Group.

Fogel, A. (1991). Infancy. St. Paul, MN: West Publishing Company.

Fogel, A., \& Thelen, E. (1987). Development of early expressive and communicative action: Reinterpreting the evidence from a dynamic systems perspective. Developmental Psychology, 23, 747-761.

Gewirtz, J.L., \& Pelaez-Nogueras, M. (1992). Social referencing as a learned process. In S. Feinman (Ed.), Social referencing and the social construction of reality in

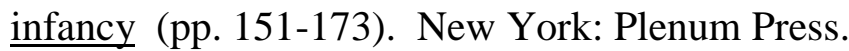

Goldsmith, H.H., \& Rothbart, M.K. (1991). Contemporary instruments for assessing early temperament by questionnaire and in the laboratory. In J. Strelau and A. Angleitner (Eds.), Explorations in temperament: International perspectives on theory and measurement. (pp. 249-272). New York: Plenum.

Haynes, S.N., Blaine, D., \& Meyer, K. (1992). Dynamical models for psychological assessment: Phase space functions. Psychological Assessment, 7, 17-24.

Hirshberg, L.M., \& Svejda, M. (1990). When infants look to their parents: I. Infants' social referencing of mothers compared to fathers. Child Development, 61, 1175-1186.

Hornik, R., Risenhoover, N., \& Gunnar, M. (1987). The effects of maternal positive, neutral, and negative affective communications on infant responses to new toys. Child Development, 58, 937-944. 
Jenkins, J.M., \& Astington, J.W. (1996). Cognitive factors and family structure associated with theory of mind development in young children. Developmental Psychology, 32, 70-78.

Kelso, J.A.S. (1995). Dynamic patterns: the self-organization of brain and behavior. Cambridge, MA: The MIT Press.

Kinderman, P., \& Dunbar, R. (1998). Theory of mind deficits and causal attributions. British Journal of Developmental Psychology, 89, 191-205.

Klinnert, M.D., Emde, R.N., Butterfield, P., \& Campos, J.J. (1986). Social referencing: The infant's use of emotional signals from a friendly adult with the mother present. Developmental Psychology, 22, 427-432.

Leung, E.H.L., \& Rheingold, H.L. (1981). Development of pointing as a social gesture. Developmental Psychology, 17, 215-220.

Lewis, M.D. (2000). The promise of dynamic systems approaches for an integrated account of human development. Child Development, 71, 36-43.

Lewis, M.D., Lamey, A.V., \& Douglas, L. (1999). A new dynamic systems method for the analysis of early socio-emotional development. Developmental Science, $\underline{2}, 457-475$.

Messer, D. (1978). The integration of mothers' referential speech with joint play. Child Development, 49, 781-787.

Moore, C., Angelopoulos, M., \& Bennett, P. (1999). Word learning in the context of referential and salience cues. Developmental Psychology, 35, 60-68.

Moore, C., \& Corkum, V. (1994). Social understanding at the end of the first year of life. Developmental Review, 14, 349-372. 
Moore, C., \& Corkum, V. (1998). Infant gaze following based on eye direction. British Journal of Developmental Psychology, 16, 495-503.

Moore, C., \& Dunham, P.J. (1995). Joint attention: Its origins and roles in development. Hillsdale, NJ: Erlbaum.

Morissette, P., Ricard, M., \& Decarie, T.G. (1995). Joint visual attention and pointing in infancy: A longitudinal study of comprehension. British Journal of Developmental Psychology, 13, 163-175.

Mumme, D.L., Fernald, A., \& Herrera, C. (1996). Infants' responses to facial and vocal emotional signals in a social referencing paradigm. Child Development, 67, 3219-3237.

Nelson, K. (1999). Levels and models of representation: Issues for the theory of conceptual change and development. In E.K. Scholnick, K. Nelson, S.A. Gelman, \& P.H. Miller (Eds.), Conceptual development: Piaget's legacy (pp. 269-291). Hillsdale, NJ:

Erlbaum.

Piaget, J. (1952). The origins of intelligence in children (M. Cook, Trans.). New York: International Universities Press. (Original work published in 1936)

Piaget, J. (1954). The construction of reality in the child (M. Cook, Trans.). New York: Basic Books. (Original work published in 1937)

Pederson, D.R., Gleason, K.E., Moran, G., \& Bento, S. (1998). Maternal attachment representations, maternal sensitivity, and the infant-mother attachment relationship. Developmental Psychology, 34, 925-933.

Repacholi, B.M. (1998). Infants' use of attentional cues to identify the referent of another person's emotional expression. Developmental Psychology, 34, 1017-1025. 
Repahcoli, B.M., \& Gopnik, A. (1997). Early reasoning about desires: Evidence from 14- and 18-month-olds. Developmental Psychology, 33, 12-21.

Reynell, J., \& Huntley, M. (1985). Reynell Developmental Language Scales (Second Revision). Windsor, England: NFER-Nelson.

Rosales-Ruiz, J., \& Baer, D.M. (1996). A behavior-analytic view of development. In S.W. Bijou \& E. Ribes (Eds.), New directions in behavior development (pp. 155-180). Reno, NV: Context Press.

Rosen, W.D., Adamson, L.B., \& Bakeman, R. (1992). An experimental investigation of infant social referencing: Mothers' messages and gender differences. Developmental Psychology, 28, 1172-1178.

Rothbart, M.K. (1981). Measurement of temperament in infancy. $\underline{\text { Child }}$ Development, 52, 569-578.

Siegler, R.S. (1996). Emerging minds: The process of change in children's thinking. New York: Oxford University Press.

Sorce, J.F., Emde, R.N., Campos, J., \& Klinnert, M.D. (1985). Maternal emotional signaling: Its effect on the visual cliff behavior of 1-year-olds. Developmental Psychology, 21, 195-200.

Stenberg, G., \& Hagekull, B. (1997). Social referencing and mood modification in 1-year-olds. Infant Behavior and Development, 20,209-217.

Thelen, E. (1995). Motor development: A new synthesis. American Psychologist, 50, 79-95.

Thelen, E., \& Smith, L.B. (1994). A dynamic systems approach to the development of cognition and action. Cambridge, MA: The MIT Press. 
van den Boom, D.C. (1994). The influence of temperament and mothering on attachment and exploration: An experimental manipulation of sensitive responsiveness among lower-class mothers with irritable infants. Child Development, 65, 1457-1477.

van Geert, P. (1994). Dynamic systems of development: Change between complexity and chaos. New York: Harvester/Wheatsheaf.

van Geert, P. (2000). The dynamics of general developmental mechanisms: From Piaget and Vygotsky to dynamic systems models. Current Directions in Psychological Science, 9, 64-68.

Walden, T.A., \& Baxter, A. (1989). The effect of context and age on social referencing. Child Development, 60, 1511-1518.

Walden, T.A., Carpenter, K.L., \& Blackford, G.K. (1999, April). When strangers are more helpful than moms: Infant referencing of parents and strangers. Poster presented at the meeting of the Society for Research in Child Development, Albuquerque, NM.

Walden, T.A., \& Ogan, T.A. (1988). The development of social referencing. Child Development, 59, 1230-1240.

Zarbatany, L., \& Lamb, M.E. (1985). Social referencing as a function of information source: Mothers versus strangers. Infant Behavior and Development, 8, 2533. 
Appendix A

\section{DYNAMICAL ANALYSIS OF INFANT SOCIAL REFERENCING}

\section{FAMILY DESCRIPTION}

Below is a series of questions that will assist us in identifying and describing the sample of children in this study. All of the information is strictly confidential. Each family will be assigned a code number and all data will be tallied without reference to individual names.

When answering these questions, please circle the number corresponding to your answer or provide the information requested. Thank you very much for your cooperation.

Today's Date:

Code \#:

Mother's Name:

Father's Name:

Mother's date of birth:

Father's date of birth:

Address:

Home Phone \#:

Mother's work phone \#:

Father's work phone \#:

Date of marriage:

Mother: Of which of the following groups do you consider yourself to be a member?

1. American Indian or Alaskan Native

2. Asian or Pacific Islander

3. Black

4. White

5. Other:

Father: Of which of the following groups do you consider yourself to be a member?

1. American Indian or Alaskan Native

2. Asian or Pacific Islander

3. Black

4. White

5. Other: 
Mother's education (Please circle the highest level of school completed):

Grade School 12234556

Junior High 7889

High School $\quad 10 \quad 11 \quad 12$

College $\quad 1234$

Degrees High School Diploma

Junior College (A.A., A.S)

B.A., B.S., B.Ed.,

M.A., M.S., M.Ed.,

Ph.D., Ed.D., M.D.,

Father's education (Please circle the highest level of school completed):

Grade School 1223456

Junior High 7889

High School $10 \quad 11 \quad 12$

College $\quad 1234$

Degrees High School Diploma

Junior College (A.A., A.S)

B.A., B.S., B.Ed.,

M.A., M.S., M.Ed.,

Ph.D., Ed.D., M.D.

Mother's present job/occupation:

Father's present job/occupation:

Household membership (Please list everyone other than yourselves and your infant who lives in your household, giving their name, age, sex, and relationship):

1 . Age

Sex Relationship

2. Age Sex Relationship

3. Age Sex Relationship

4. Age Sex Relationship

5. Age Sex Relationship

Did you experience any problems or complications during this pregnancy?

1. No

2. Yes 
If yes, please explain:

How frequently did you receive prenatal care?

1. Approximately once a month or more often

2. Irregularly throughout the pregnancy

3. Once, during the first month of the pregnancy

4. Once, in the middle of the pregnancy

5. Once, at the end of the pregnancy

6. Never

If you did receive prenatal care, where did you receive it?

1. Private doctor

2. $\mathrm{HMO}$

3. Hospital clinic

4. Public health clinic

5. Midwife

6. Other:

If you did not receive prenatal care, why?

1. I did not like the care I had received previously.

2. I did not think it was necessary.

3. I did not have the money or insurance to cover it.

4. I feared going to a hospital and/or having medical procedures.

5. I did not have the time because of work or school.

6. I was treated badly during my first visit.

7. Other (Please explain):

Did you prepare for labor and delivery by attending a prepared childbirth course (for example, LaMaze, etc.)?
1. No

2. Yes 


\section{INFANT DESCRIPTION}

Below is a series of questions that will assist us in identifying and describing the sample of children in this study. All of the information is strictly confidential. Each family will be assigned a code number and all data will be tallied without reference to individual names.

When answering these questions, please circle the number corresponding to your answer or provide the information requested. Thank you very much for your cooperation.

Today's Date:

Code \#:

Child's name:

Child's sex:

1. Female

2. Male

Date of birth:

Birthweight:

Length at birth:

Maturity at birth:

1. Preterm (Born three or more weeks before due date)

2. Term (Born within three weeks of due date)

3. Postterm (Born more than three weeks after due date)

4. Don't know

Please explain:

Has the child experienced any serious illnesses or problems in development since birth (i.e., diagnosed congenital conditions or medical issues requiring hospitalization, outpatient emergency room treatment, consultation with a specialist, or frequent monitoring by your own doctor)?

1. No

2. Yes

If yes, please explain: 
Does your infant have any diagnosed problems with sight or hearing?

1. No

2. Yes

If yes, please explain:

Will your infant be exposed to any language other than English on a regular basis (e.g. through grandparents or a child care giver)?
1. No
2. Yes

Was a relative or friend present at the delivery to assist you?

1. No

2. Yes

If yes, who was it?

Type of delivery:

1. Vaginal

2. Cesarean

Did you receive any medication during labor or delivery?

1. None

2. Demerol

3. Neuromuscular block (epidural spinal, caudal, etc.)

4. Unsure

5. Other

Please describe:

Did you experience any problems or complications during labor and delivery?

1. No

2. Yes

If yes, please explain:

Did you and the baby come home from the hospital together?

1. Yes

2. No

If no, please describe what happened: 
Did your baby exhibit any of the following behaviors during his or her first weeks at home?

1. Excessive vomiting

Yes

No

2. Prolonged or frequent diarrhea or constipation

3. Pronounced lack of interest in being fed or an active refusal to eat

4. Excessive demand to be fed

5. Frequent waking and crying at night

6. Excessive sleeping during the day

7. Frequent and intense crying generally

8. Lack of interest in things going on around him or her when awake and alert

9. Noticeable stiffening, turning away, or crying when picked up or handled

10. Pronounced clinging when picked up or intense crying when put down

\section{Comments:}




\section{Appendix B}

Noise

Car Crash

Electric Saw

Train Leaving Station

Electric Drill

Ship Alarm

Hand Saw

Swarm of Bees

Pigs

Wasp

Geese and Ducks

Frogs

Chicken Coop

Alarm Clock

Horse

Firecrackers

Creaking Door Closing

Geese

Creaking Door Opening

Regal Fanfare

Diesel Train

Marshal Fanfare
Maximum Decibel Level

$76 \mathrm{~dB}$

$90 \mathrm{~dB}$

$70 \mathrm{~dB}$

$90 \mathrm{~dB}$

$80 \mathrm{~dB}$

$82 \mathrm{~dB}$

$74 \mathrm{~dB}$

$84 \mathrm{~dB}$

$78 \mathrm{~dB}$

$92 \mathrm{~dB}$

$80 \mathrm{~dB}$

$76 \mathrm{~dB}$

$78 \mathrm{~dB}$

$90 \mathrm{~dB}$

$80 \mathrm{~dB}$

$78 \mathrm{~dB}$

$84 \mathrm{~dB}$

$80 \mathrm{~dB}$

$84 \mathrm{~dB}$

$84 \mathrm{~dB}$

$82 \mathrm{~dB}$ 
Noise

Cable Car

Helicopter Landing

Dentist Water Drill

Angry Crowd

Motor Start and Run
Maximum Decibel Level

$74 \mathrm{~dB}$

$70 \mathrm{~dB}$

$90 \mathrm{~dB}$

$80 \mathrm{~dB}$

$84 \mathrm{~dB}$ 


\section{Appendix C}

\section{SOCIAL REFERENCING DATA SHEET-INFANT \\ Dynamical Analysis of Infant Social Referencing}

Participant \#:___ Date:____ Experimenter:

Stimulus:____ Stranger ___ Noise ___Puppet Show ___ Other

Context: ___ Lab ___ Home

Noise only: ___ $1^{\text {st }}$ noise $\_2^{\text {nd }}$ noise Stranger only: ___ before ___ after

Please rate the infant's initial affect as one of following:

$1=$ positive (interested, eager, excited, happy)

$2=$ neutral (quizzical, attentive, concerned, slightly worried)

$3=$ negative (scared, nervous, disinterested)

Rating:

Please record the number of times the infant looks to the referee after looking to the stimulus over the course of the assessment:

Please record the manner in which the infant responds to the stimulus after the referee responds toward it:

$1=$ Positively_-infant responds to the stimulus with obvious joy and interest; approach to the stimulus may be observed; positive affect is evident.

$2=$ Negatively —infant responds to the stimulus with obvious fear; no approach is observed and the infant may even retreat; negative affect is evident.

$3=$ Other-infant's response is ambiguous and cannot be discerned as either positive or negative according to the definitions provided above.

Rating: 


\section{Appendix D}

JOINT ATTENTION DATA SHEET

Dynamical Analysis of Infant Social Referencing

Participant \#:__ Date: __ _ Experimenter:

Task:__Eye __ Head __ Point

Please rate the infant's behavior as one of the following:

1=infant either continues looking at the mother, looks to the opposite side of what is indicated, or looks to both sides.

$2=$ infant looks only at the pointing hand

$3=$ infant looks on the side indicated, but does not look at the specific target

4=infant looks at the wrong target on the correct side, or looks at the wrong target on the correct side and then looks at the correct target

$5=$ infant looks directly at the correct target.

Rating: 
Table 1

$\underline{\text { Infants' Language Comprehension Scores as Measured by the MCDI }}{ }^{\mathrm{a}}$ and $\operatorname{RDLS}^{\mathrm{b}}$ at Ages 7, 9, and 11 Months

\begin{tabular}{lcccccc}
\hline & \multicolumn{3}{c}{ MCDI } & & \multicolumn{3}{c}{ RDLS } \\
\cline { 2 - 3 } \cline { 5 - 6 } Infant & 7 & 9 & 11 & 7 & 9 & 11 \\
\hline $1(\mathrm{~F} ; 7 \mathrm{~m}, 0 \mathrm{~d})$ & 75 & 63 & 70 & 5 & 9 & $17(2.3)$ \\
$2(\mathrm{M} ; 7 \mathrm{~m}, 4 \mathrm{~d})$ & 10 & 17 & 25 & 3 & 8 & $11(.9)$ \\
$3(\mathrm{~F} ; 7 \mathrm{~m}, 2 \mathrm{~d})$ & 5 & $>5$ & $>5$ & 3 & 12 & $12(1.2)$ \\
$4(\mathrm{M} ; 7 \mathrm{~m}, 21 \mathrm{~d})$ & 30 & 15 & 47 & 5 & 10 & $15(1.8)$ \\
$5(\mathrm{M} ; 6 \mathrm{~m}, 29 \mathrm{~d})$ & 50 & 70 & 87 & 4 & 12 & $13(1.4)$ \\
\hline
\end{tabular}

Note. Infants' gender and age in months and days are represented in parentheses following the infants' number. Infants' RDLS standard scores, based on the 12-month scale, are indicated in parentheses following their 11-month raw scores.

${ }^{a}$ Percentile scores. ${ }^{b}$ Raw scores. 
Table 2

Infants' Percentage Scores on Each Dimension of the HOME at Times of Measurement 1, 2, and 3

\begin{tabular}{|c|c|c|c|c|c|c|c|c|c|c|c|c|c|c|c|c|c|c|}
\hline \multirow[b]{2}{*}{$\underline{\text { Infant }}$} & \multicolumn{3}{|c|}{$\mathrm{RES}^{\mathrm{a}}$} & \multicolumn{3}{|c|}{$\mathrm{PUN}^{\mathrm{b}}$} & \multicolumn{3}{|c|}{$\mathrm{ENV}^{\mathrm{c}}$} & \multicolumn{3}{|c|}{$\mathrm{PLY}^{\mathrm{d}}$} & \multicolumn{3}{|c|}{$\mathrm{INV}^{\mathrm{e}}$} & \multicolumn{3}{|c|}{ VAR $^{\mathrm{f}}$} \\
\hline & 1 & 2 & 3 & 1 & 2 & 3 & 1 & 2 & 3 & 1 & 2 & 3 & 1 & 2 & 3 & 1 & 2 & 3 \\
\hline 1 & 90 & 90 & 90 & 88 & 88 & 88 & 100 & 100 & 100 & 88 & 77 & 88 & 83 & 100 & 83 & 60 & 60 & 60 \\
\hline 2 & 90 & 81 & 81 & 100 & 88 & 88 & 100 & 83 & 100 & 67 & 55 & 88 & 83 & 66 & 83 & 80 & 60 & 60 \\
\hline 3 & 90 & 90 & 90 & 75 & 88 & 88 & 100 & 100 & 100 & 77 & 66 & 66 & 83 & 83 & 83 & 60 & 60 & 60 \\
\hline 4 & 90 & 90 & 90 & 100 & 100 & 100 & 100 & 100 & 100 & 77 & 44 & 33 & 83 & 66 & 100 & 60 & 60 & 60 \\
\hline$\underline{5}$ & 90 & 90 & 90 & 88 & 88 & 88 & 100 & 100 & 100 & 66 & 66 & 66 & 83 & 83 & 83 & 60 & 60 & 60 \\
\hline
\end{tabular}

${ }^{a}$ Emotional and verbal responsivity of the mother. ${ }^{\mathrm{b}}$ Avoidance of restriction and punishment. ${ }^{\mathrm{c}}$ Organization of physical and temporal environment. ${ }^{\mathrm{d}}$ Provision of appropriate play materials. ${ }^{\mathrm{e}}$ Maternal involvement with child. ${ }^{\mathrm{f}}$ Opportunities for variety in daily stimulation. 
Table 3

$\underline{\text { IBQ Scores on Dimensions of Distress and Latency to Approach Novel Stimuli and }}$

$\underline{\text { Smiling and Laughter at Times of Measurement 1,2, and } 3}$

\begin{tabular}{|c|c|c|c|c|c|c|}
\hline \multirow[b]{2}{*}{ Infant } & \multicolumn{3}{|c|}{ Distress $^{\text {a }}$} & \multicolumn{3}{|c|}{ Smiling $^{\mathrm{b}}$} \\
\hline & 1 & 2 & 3 & 1 & 2 & 3 \\
\hline 1 & 1.75 & 2.50 & 2.43 & 6.18 & 5.82 & 5.82 \\
\hline 2 & 2.88 & 2.00 & 1.88 & 3.82 & 3.45 & 4.18 \\
\hline 3 & 2.29 & 1.57 & 2.00 & 4.91 & 6.55 & 5.91 \\
\hline 4 & 2.57 & 1.57 & 2.93 & 5.17 & 3.50 & 3.75 \\
\hline 5 & 1.13 & 2.13 & 1.40 & 6.73 & 6.64 & 2.13 \\
\hline
\end{tabular}

${ }^{a}$ Distress and latency to approach novel stimuli. ${ }^{\mathrm{b}}$ Smiling and laughter. 


\section{Figure Captions}

Figure 1a. MCDI raw scores, by infant, by weeks after the onset of participation in study. Figure 1b. Total number of communicative gestures as measured by the MCDI, by infant, by weeks after the onset of participation in the study.

$\underline{\text { Figure 2. }}$ Mean number of looks in all three paradigms, by infant, by weeks after the onset of participation in the study.

Figure 3. Mean number of looks before the pickup and looks after the pickup, by infant, by weeks after the onset of participation in the study, in the stranger paradigm.

Figure 4. Mean number of looks by the first time a noise was played and the second time that same noise was played, by infant, by weeks after the onset of participation in the study, in the noise paradigm.

Figure 5. Mean number of looks by social referencing tasks in the home and in the laboratory, by infant, by weeks after the onset of participation in the study.

Figure 6. Infants' joint visual attention and comprehension of pointing scores, by infants, by weeks after the onset of participation in the study.

Figure 7. Infant 1 data, shown left to right, top to bottom: MCDI raw scores, communicative gestures, social referencing, social referencing noise, social referencing stranger, and joint visual attention and comprehension of pointing.

Figure 8. Infant 2 data, shown left to right, top to bottom: MCDI raw scores, communicative gestures, social referencing, social referencing noise, social referencing stranger, and joint visual attention and comprehension of pointing. 
Figure 9. Infant 3 data, shown left to right, top to bottom: MCDI raw scores, communicative gestures, social referencing, social referencing noise, social referencing stranger, and joint visual attention and comprehension of pointing.

Figure 10. Infant 4 data, shown left to right, top to bottom: MCDI raw scores, communicative gestures, social referencing, social referencing noise, social referencing stranger, and joint visual attention and comprehension of pointing.

Figure 11. Infant 5 data, shown left to right, top to bottom: MCDI raw scores, communicative gestures, social referencing, social referencing noise, social referencing stranger, and joint visual attention and comprehension of pointing. 
Social Referencing 52

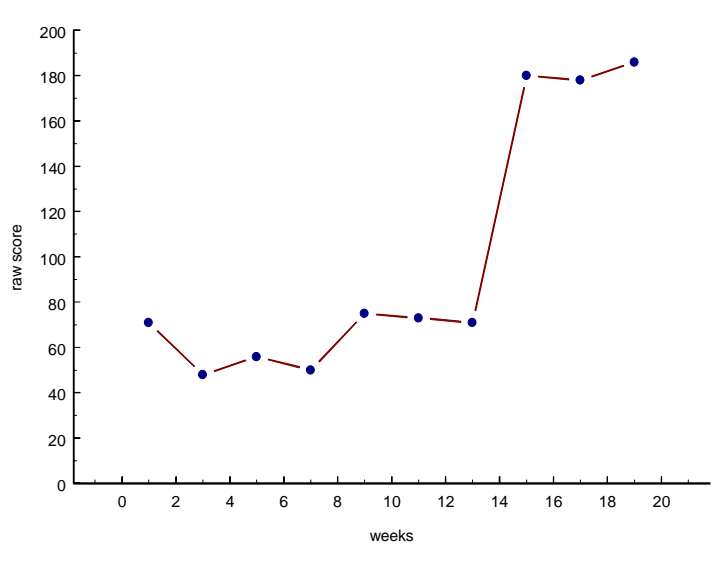

13

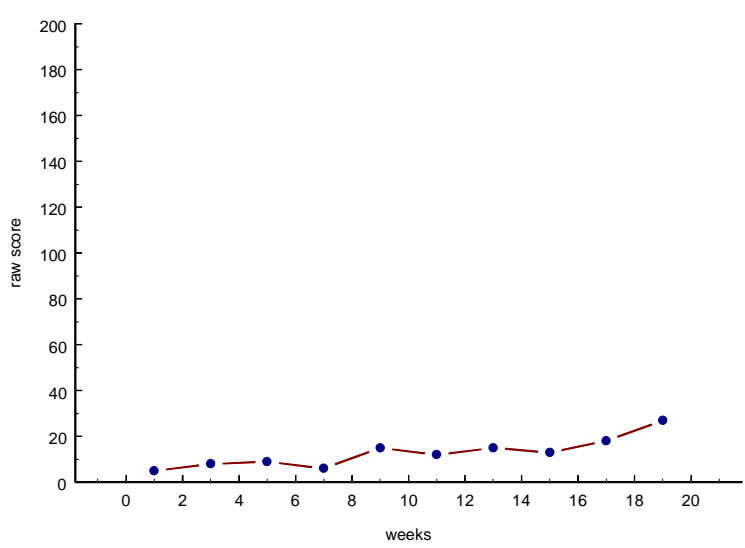

12

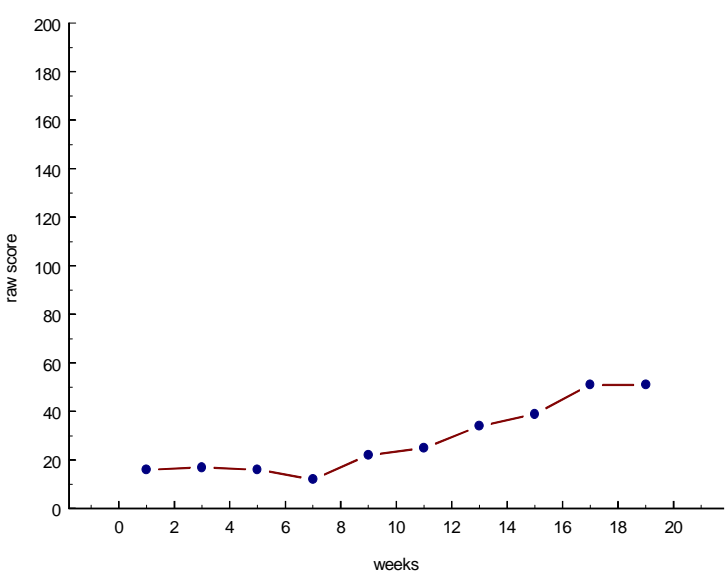

14

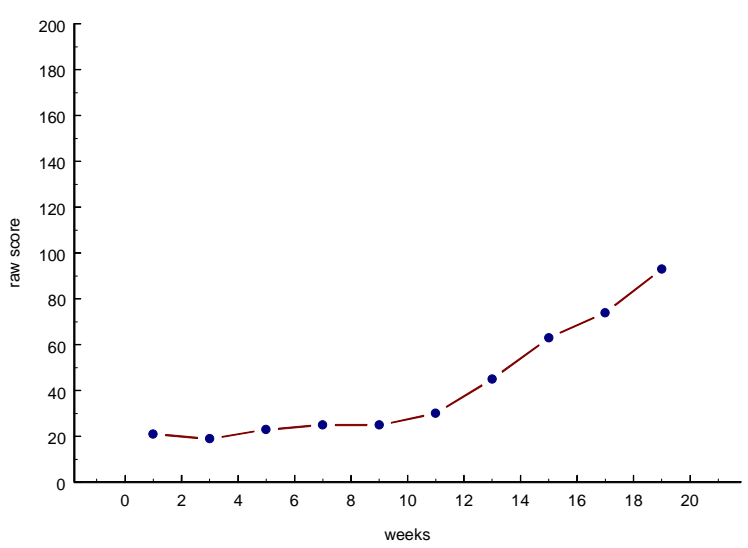

15

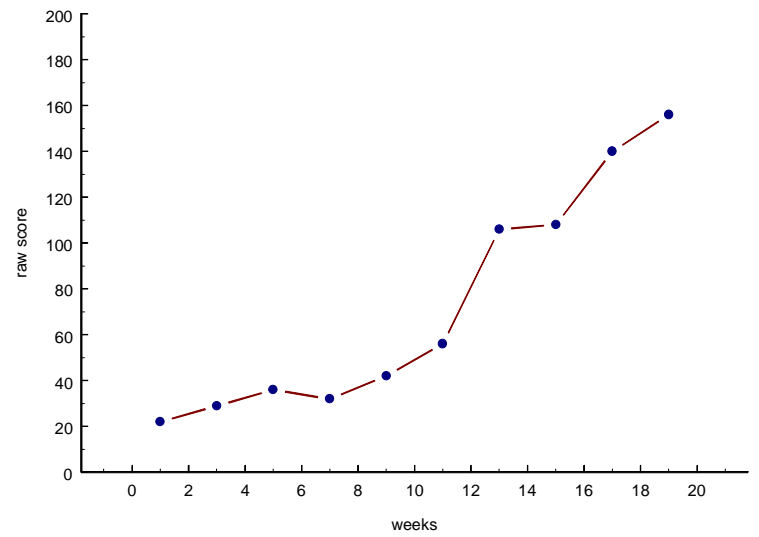

Figure 1a. 
Social Referencing 53

11



13

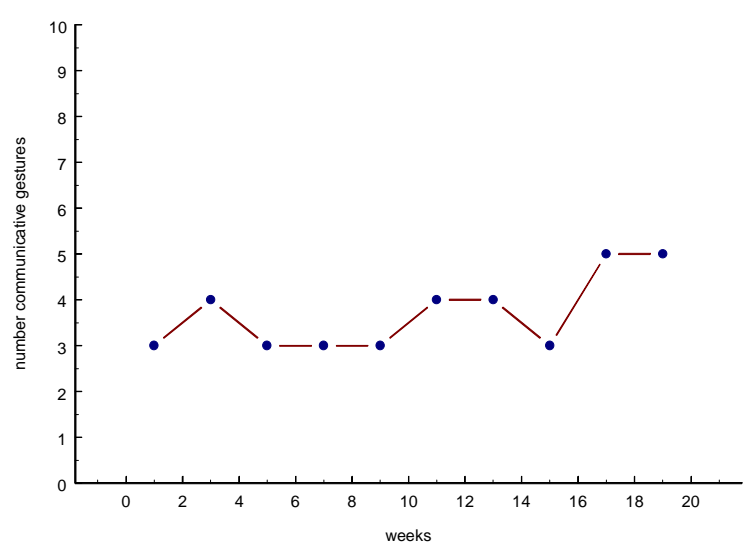

12

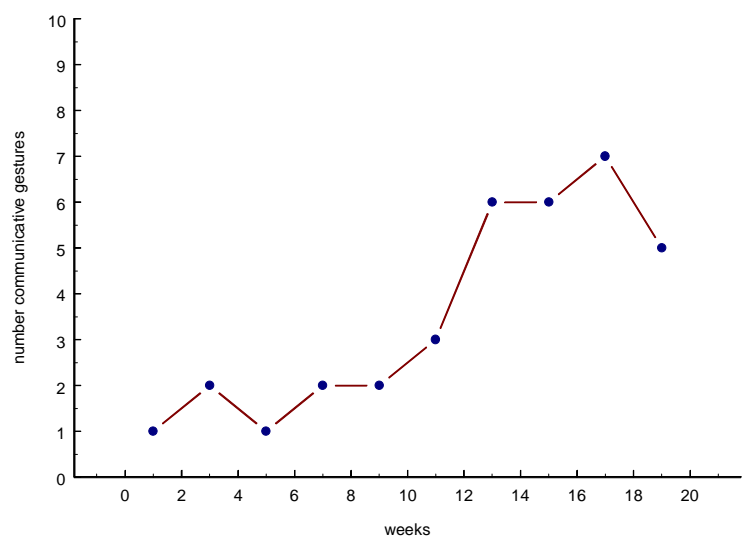

14

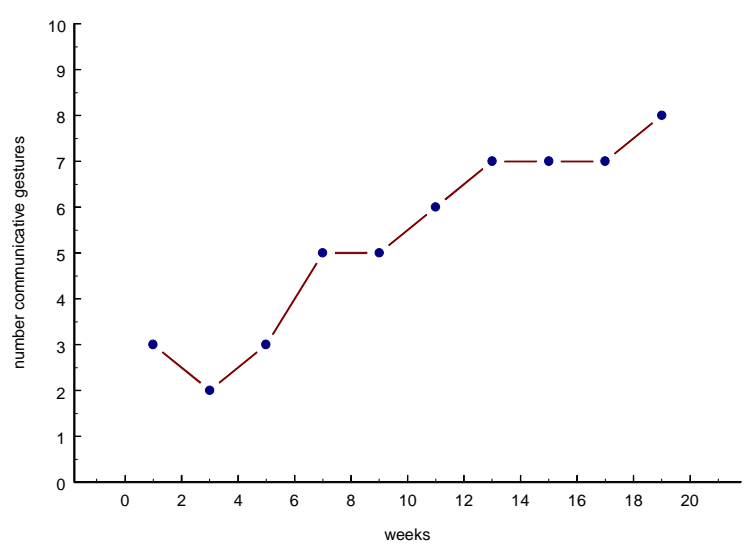

15

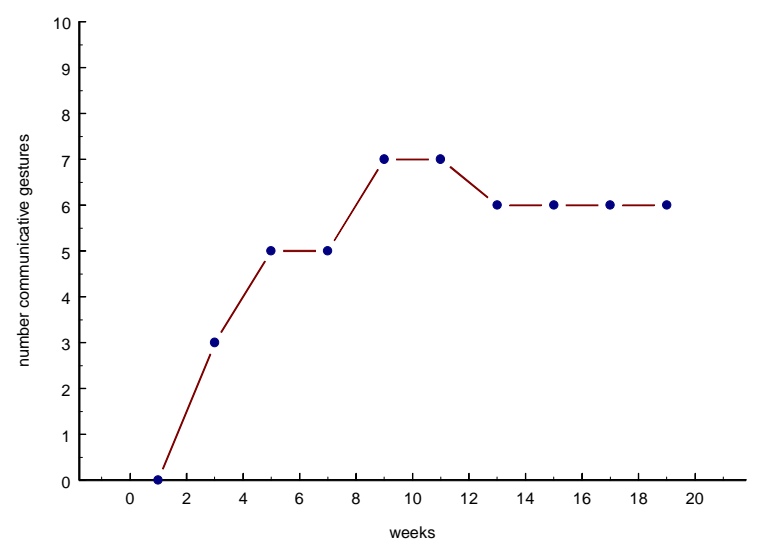

Figure 1b. 
11

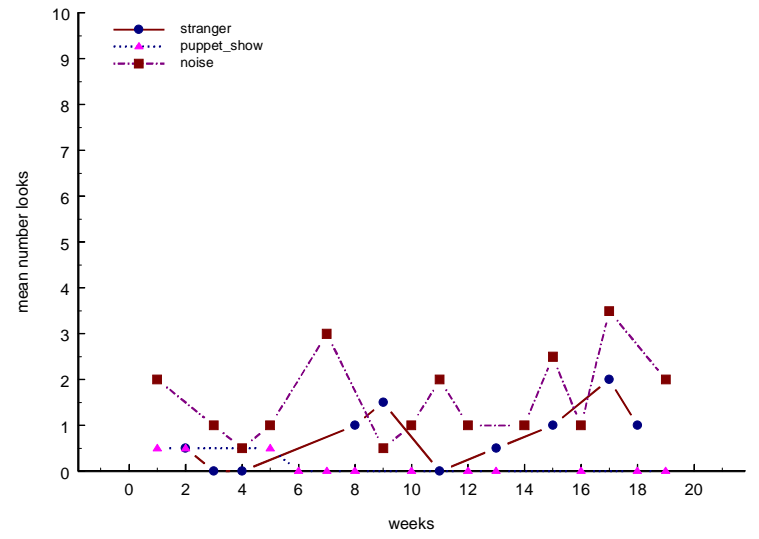

13

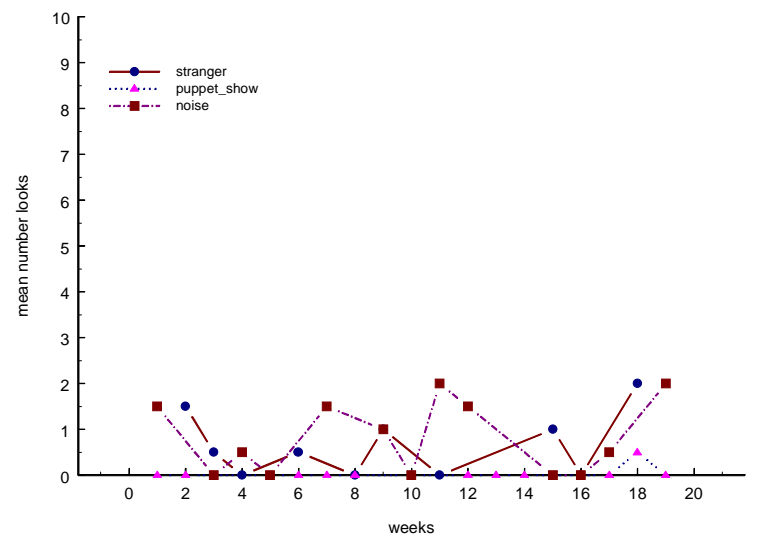

12

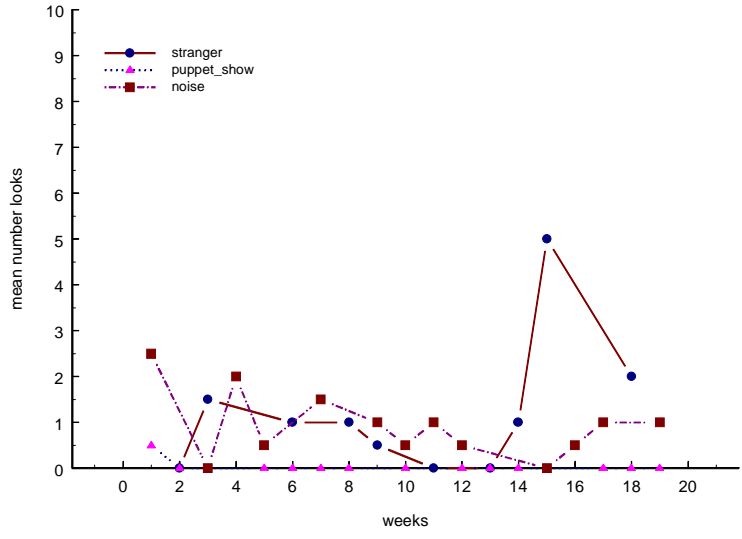

14



15

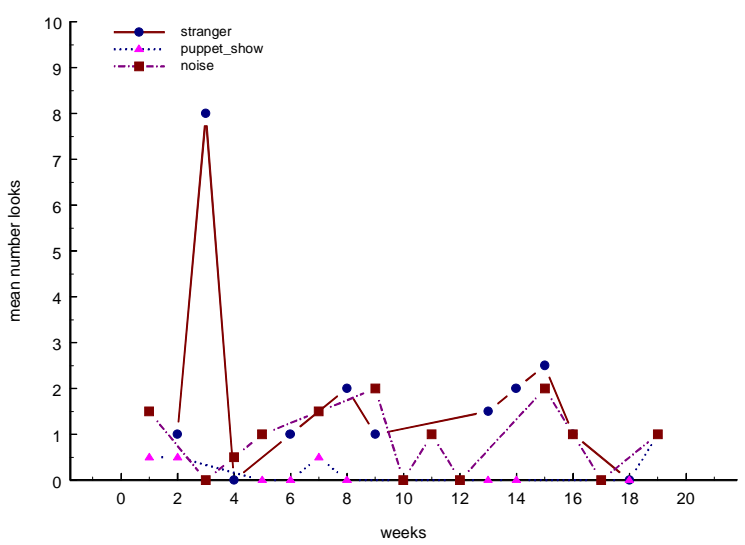

Figure 2. 
Social Referencing 55

1
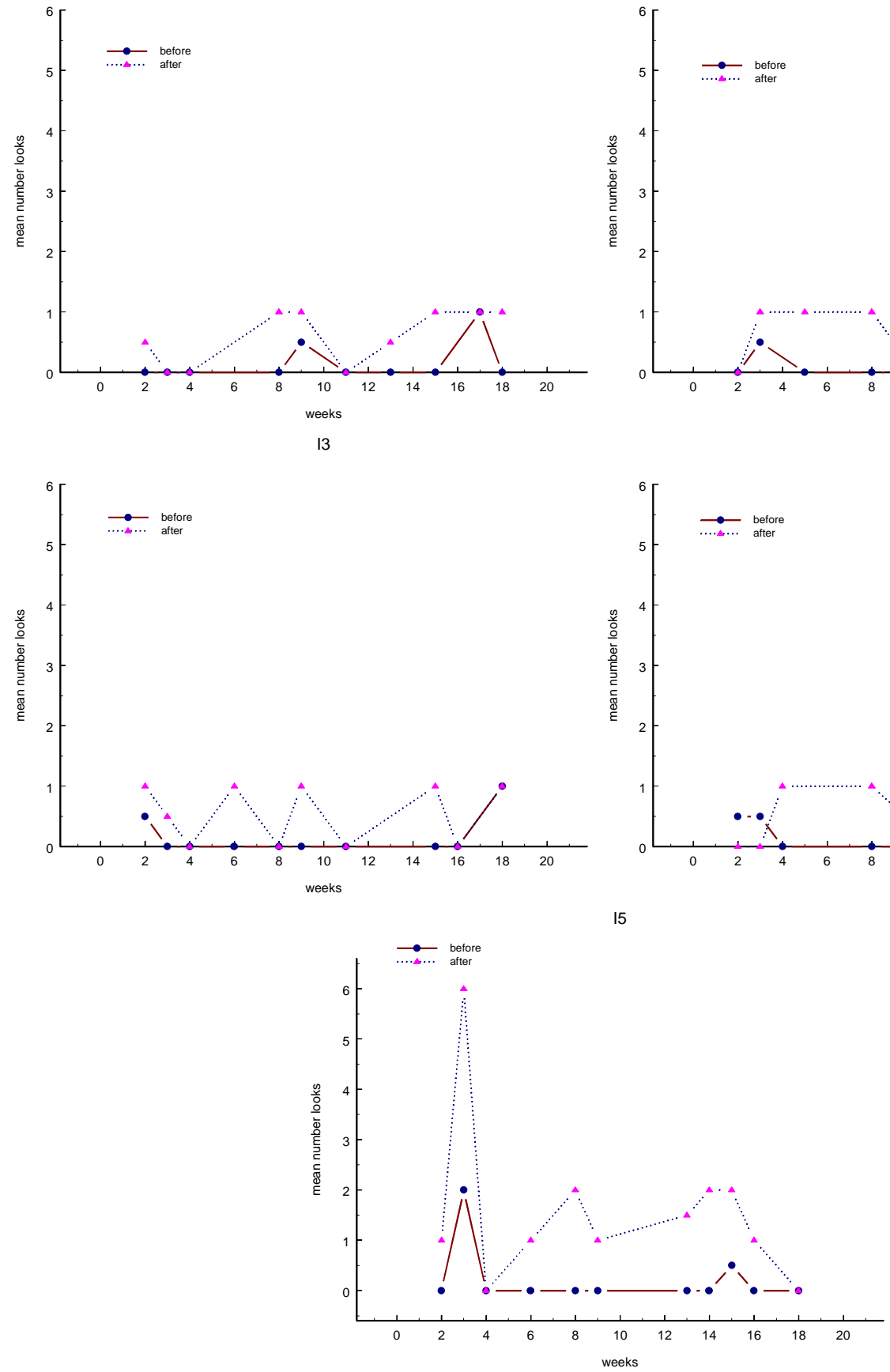

12
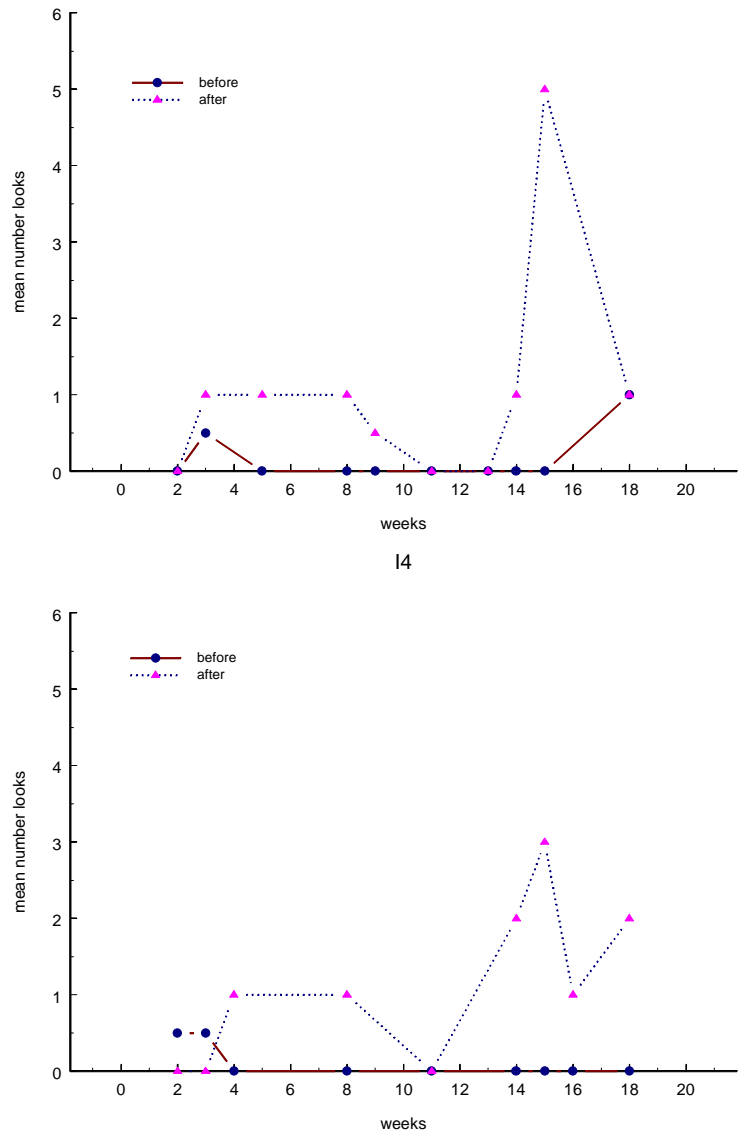

15

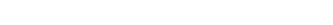


11

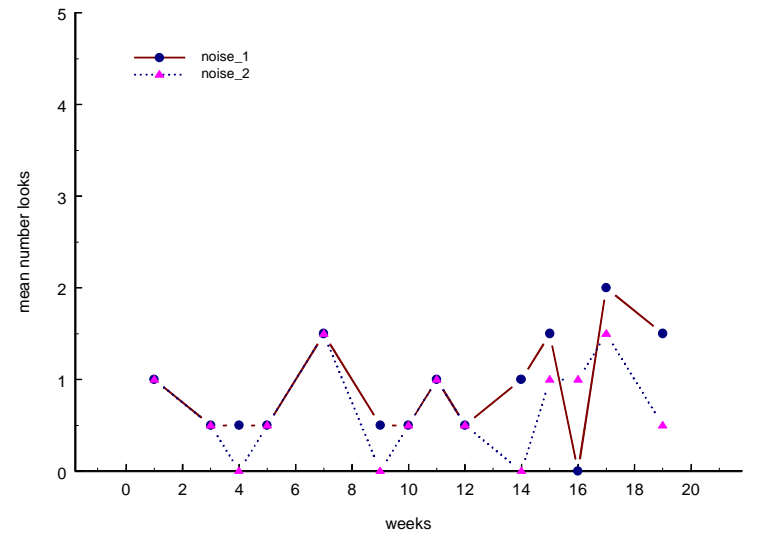

13

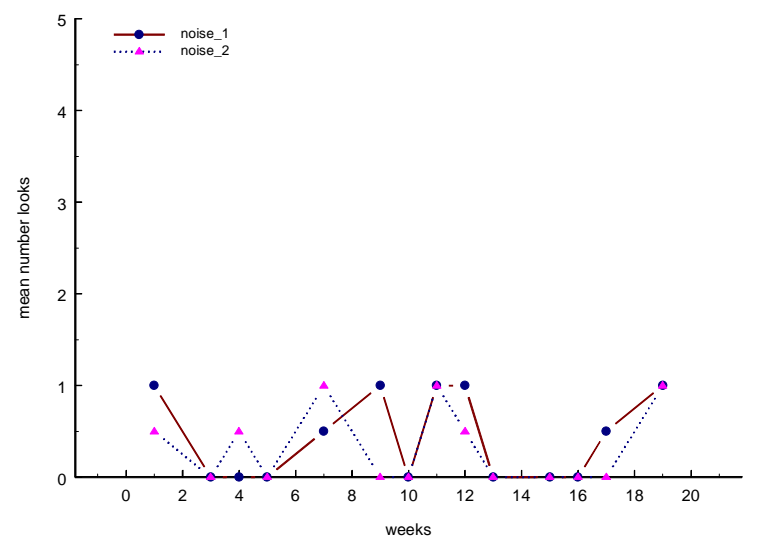

12

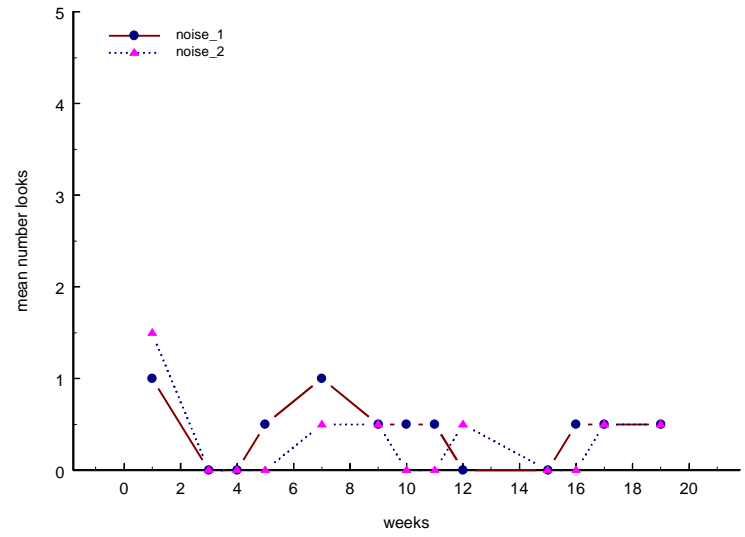

14

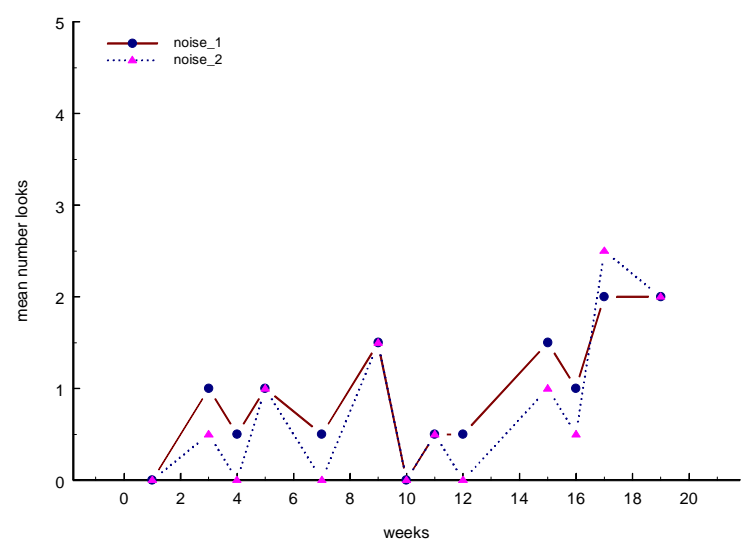

15

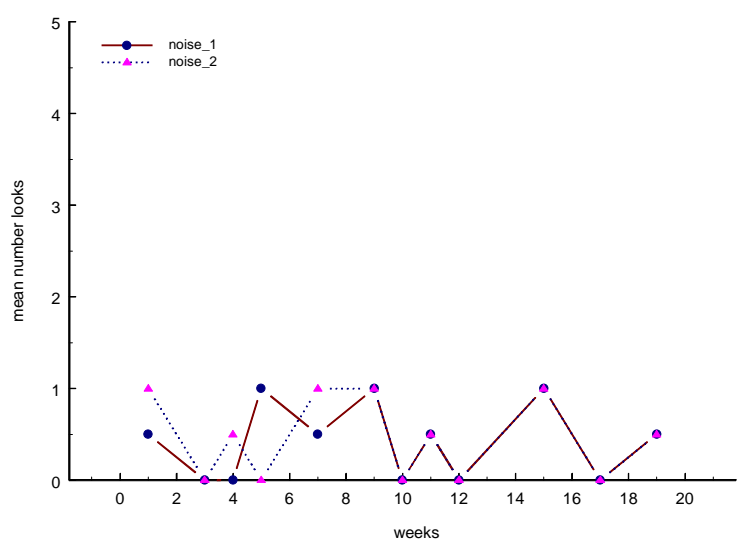

Figure 4. 
11


12
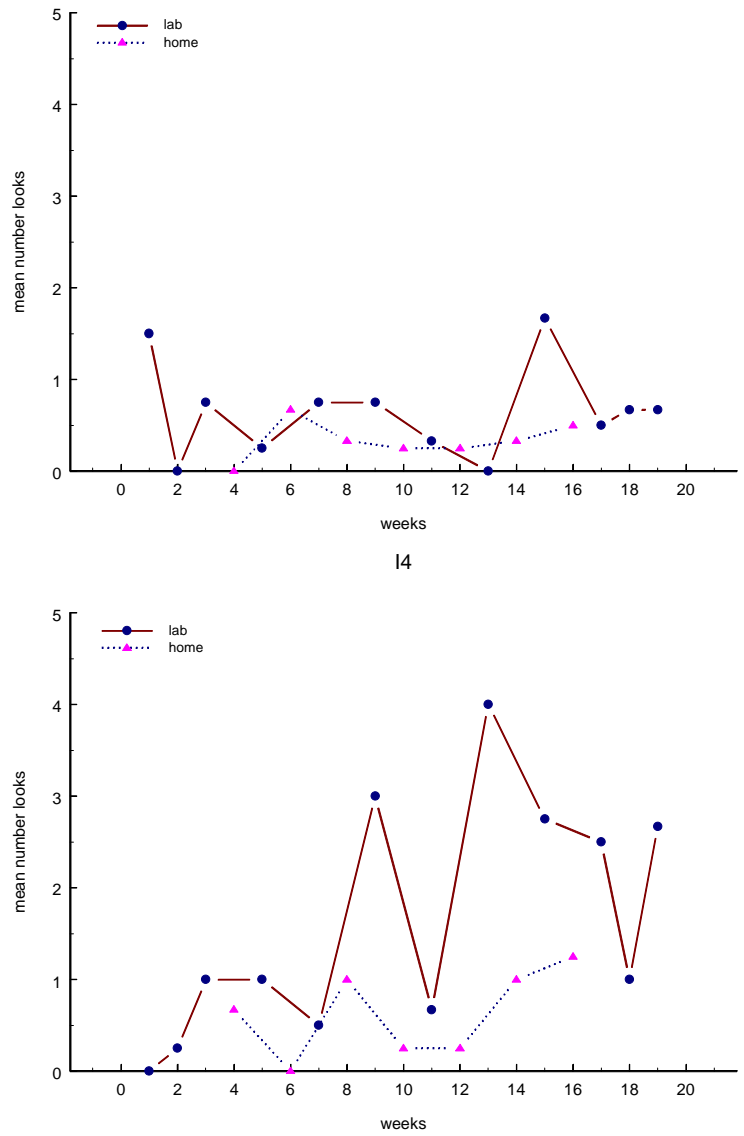

15

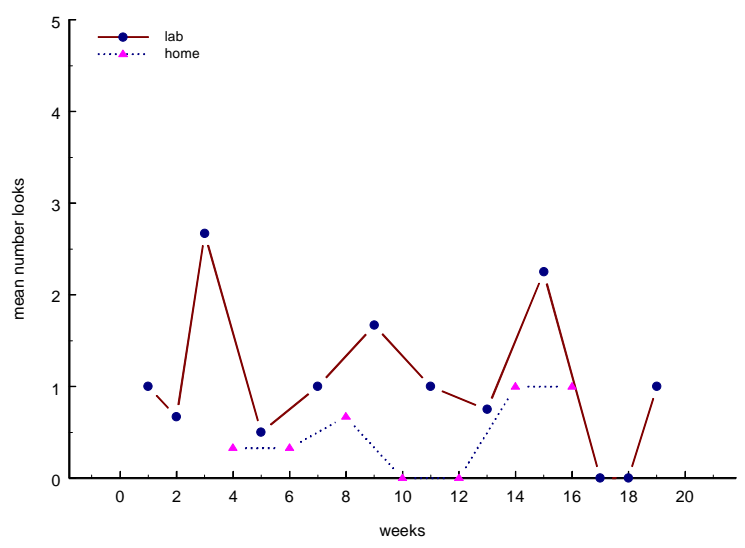

Figure 5. 
Social Referencing 58

11

12
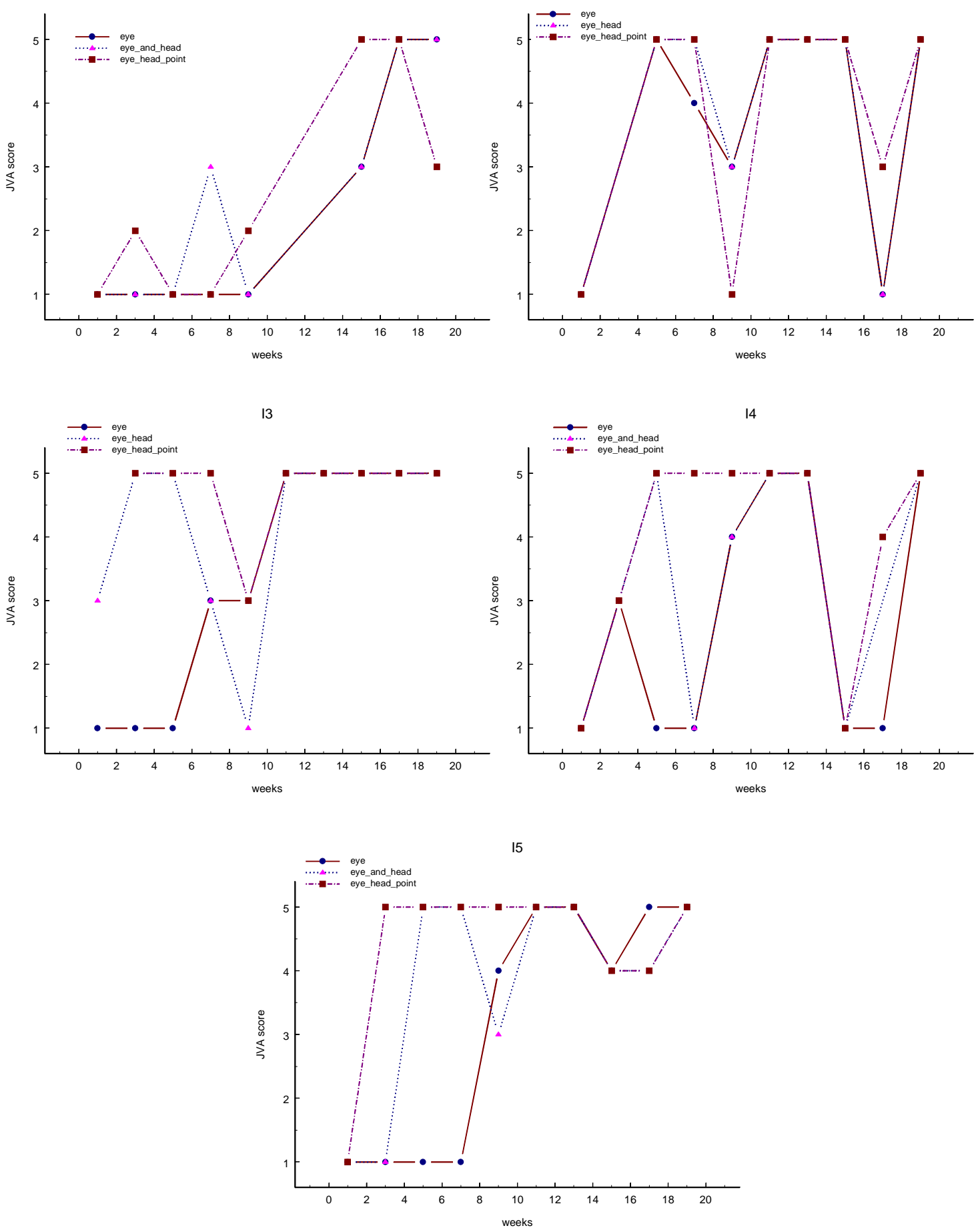

Figure 6. 
Social Referencing 59
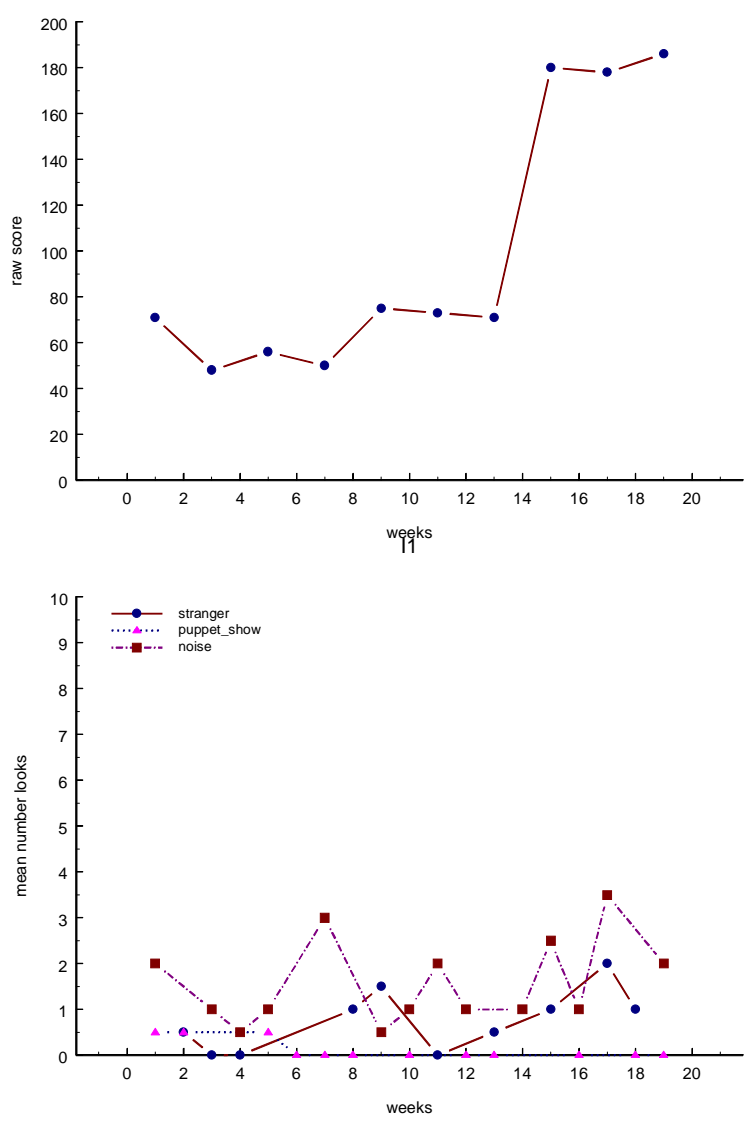

I1



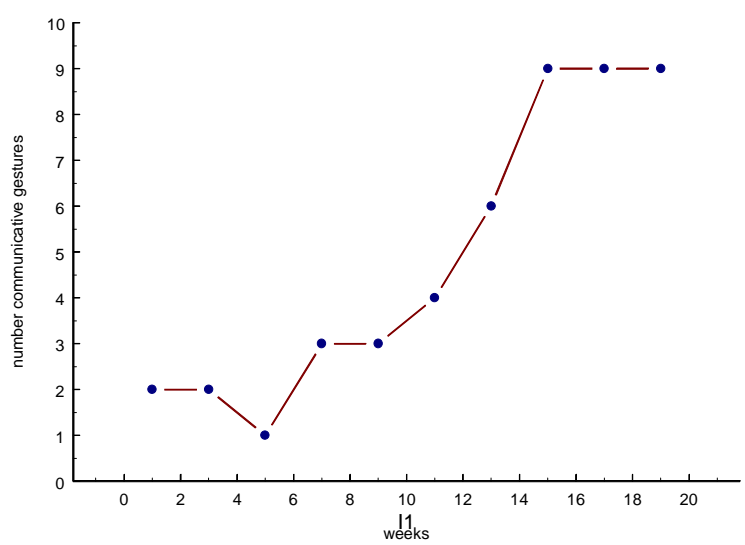

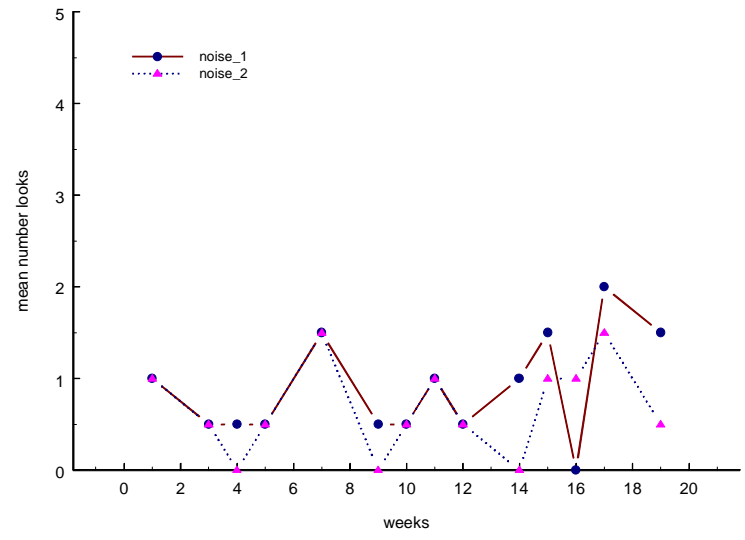

I1

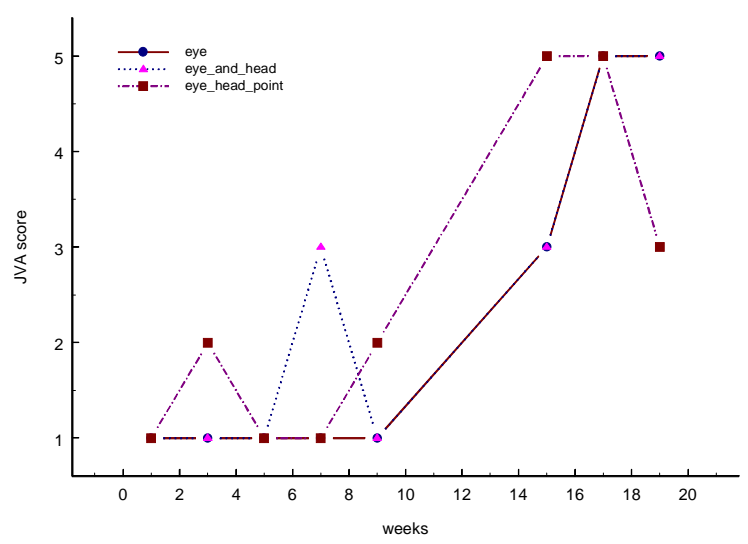

Figure 7. 
12

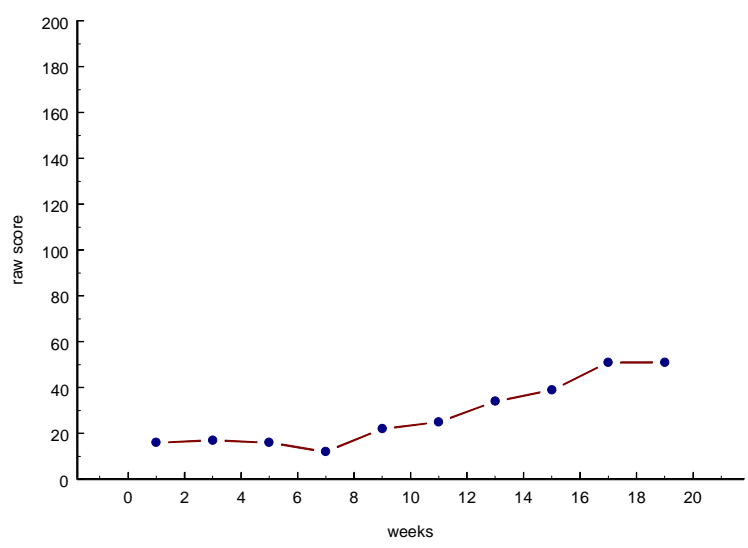

12

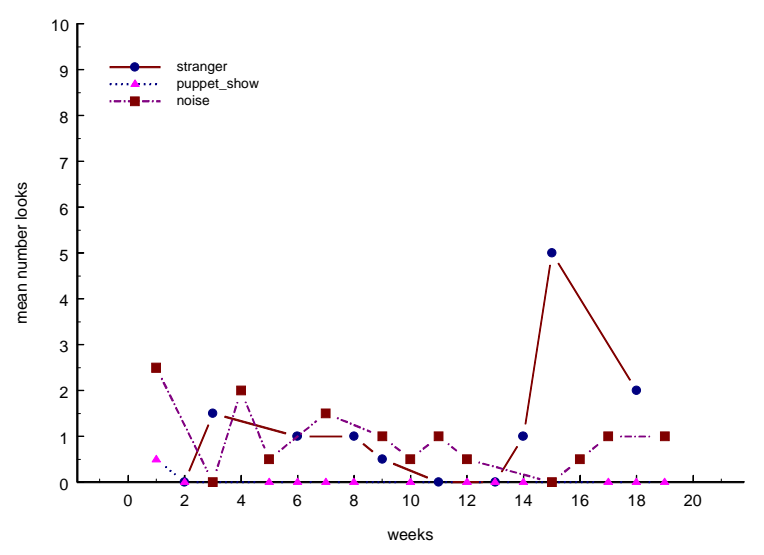

12

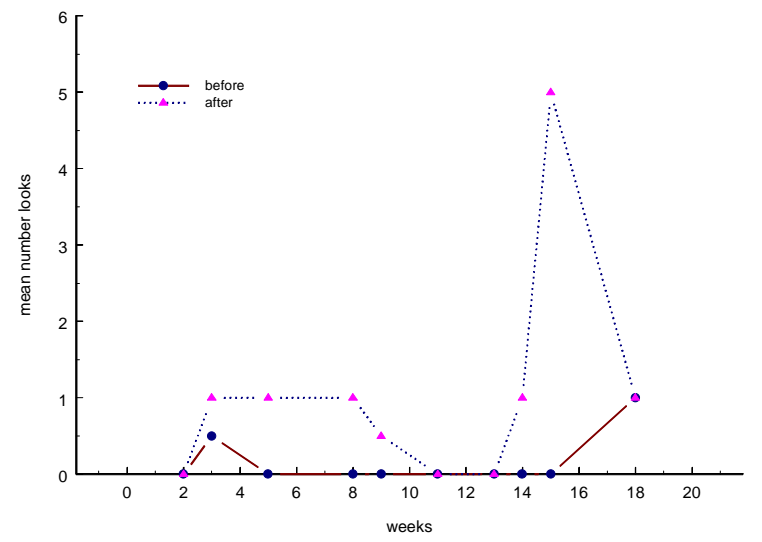



12

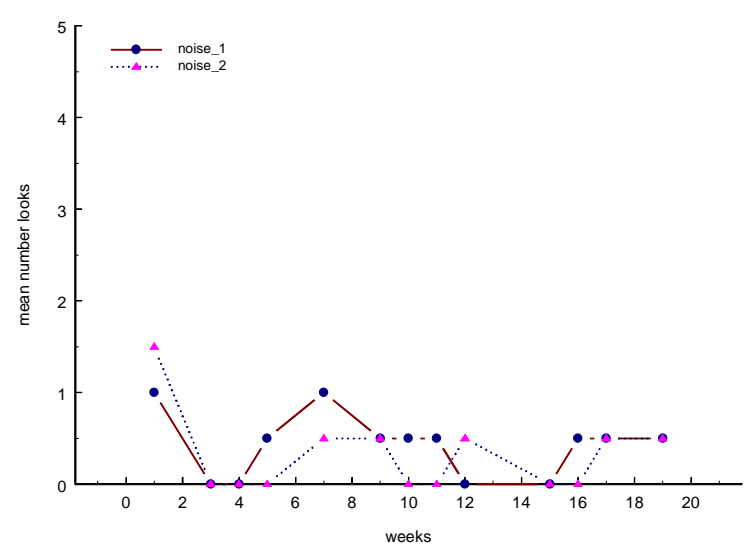

12

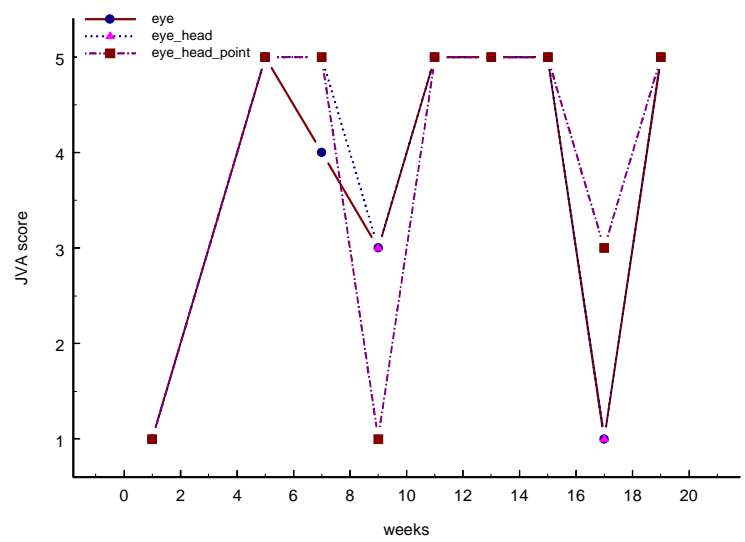

Figure 8. 
13

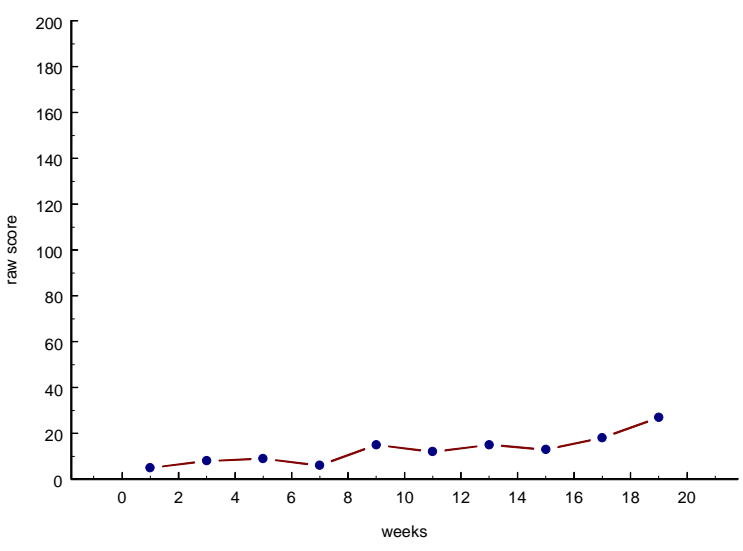

13

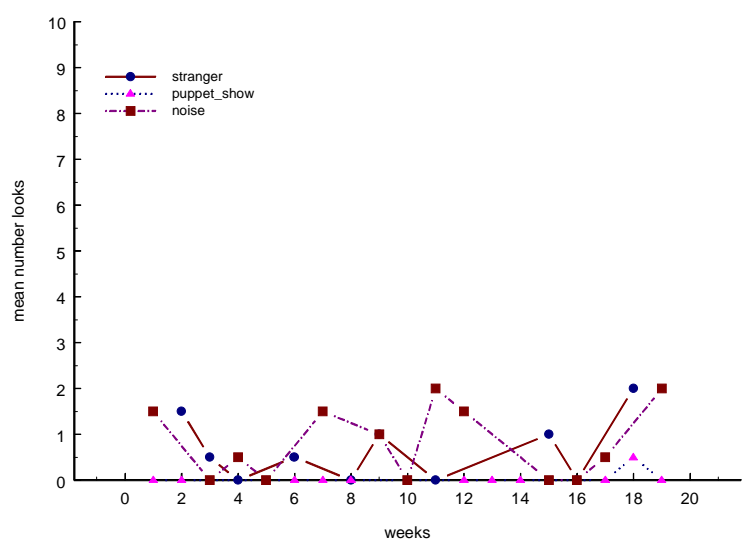

13

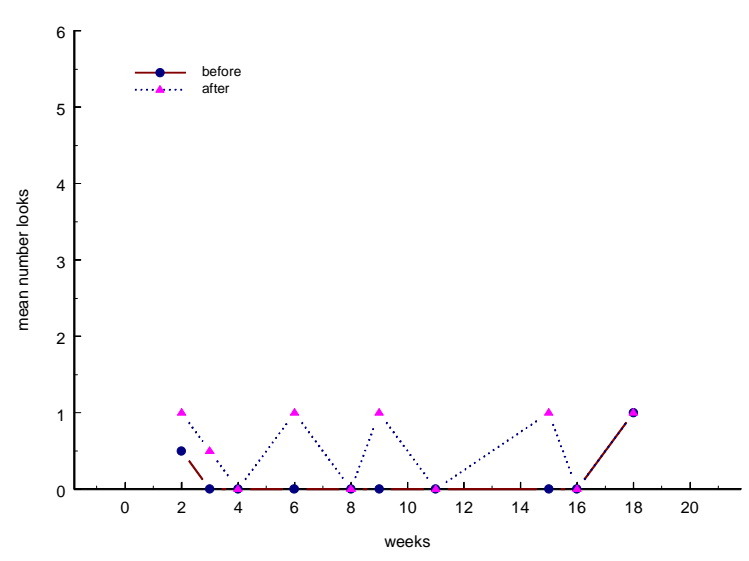

13
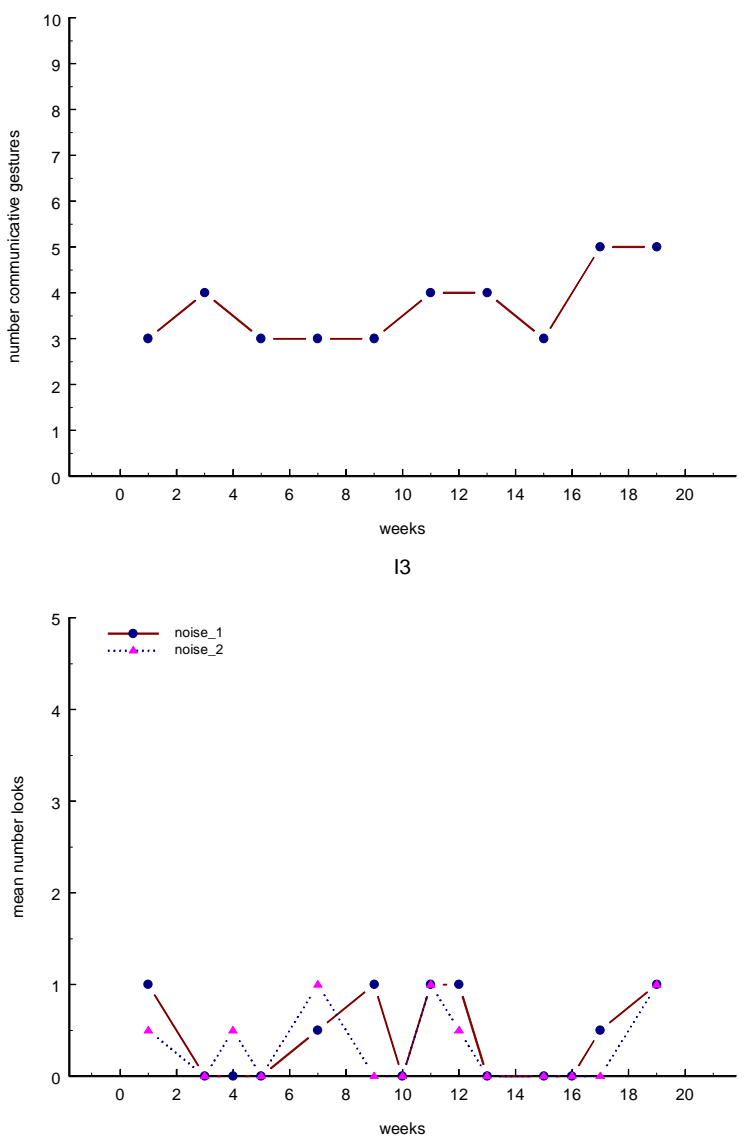

13



Figure 9. 
14
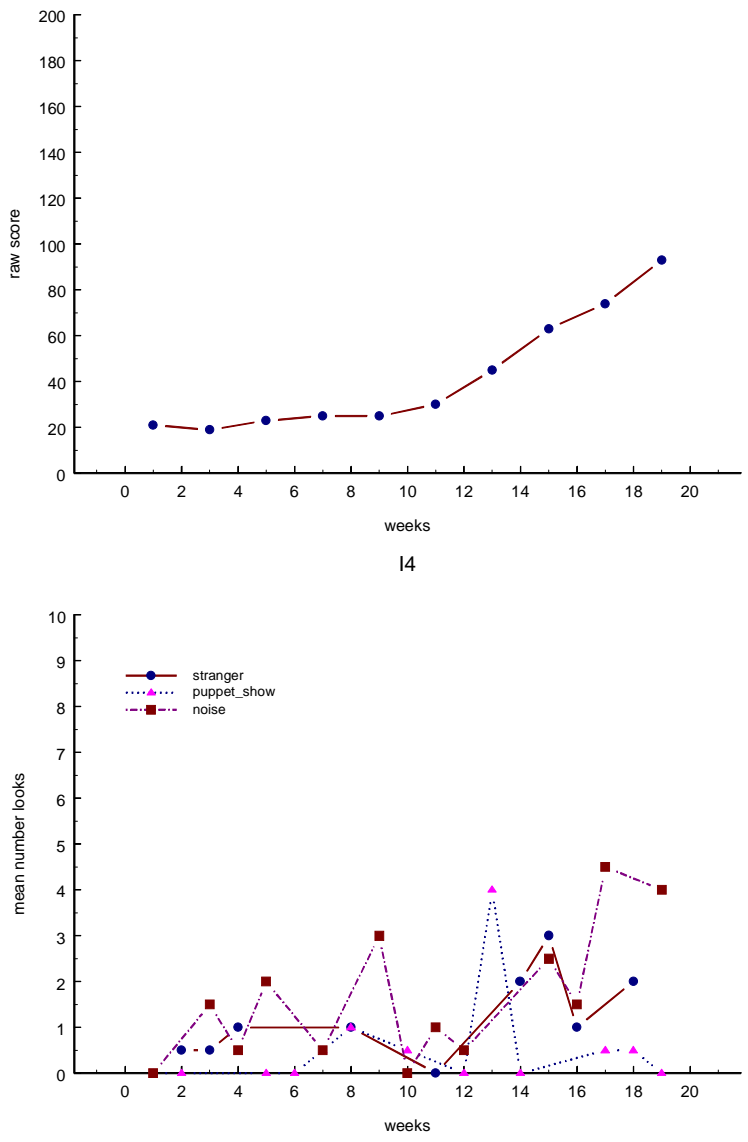

14



14
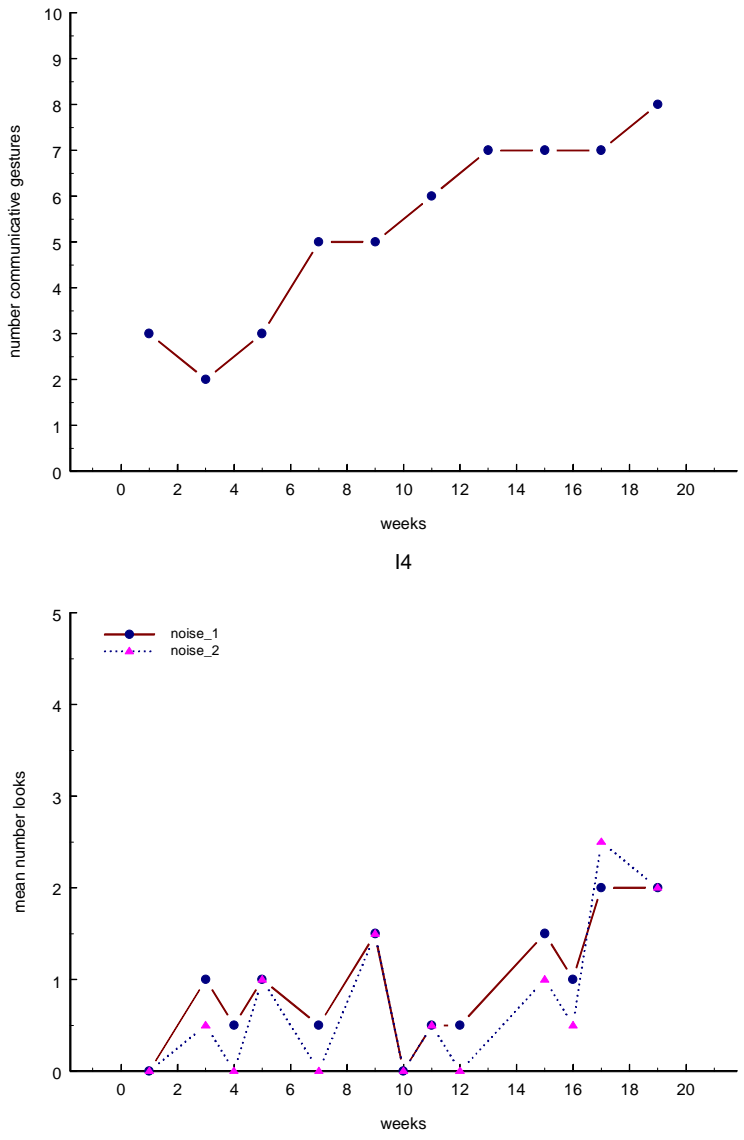

14



Figure 10. 
Social Referencing 63

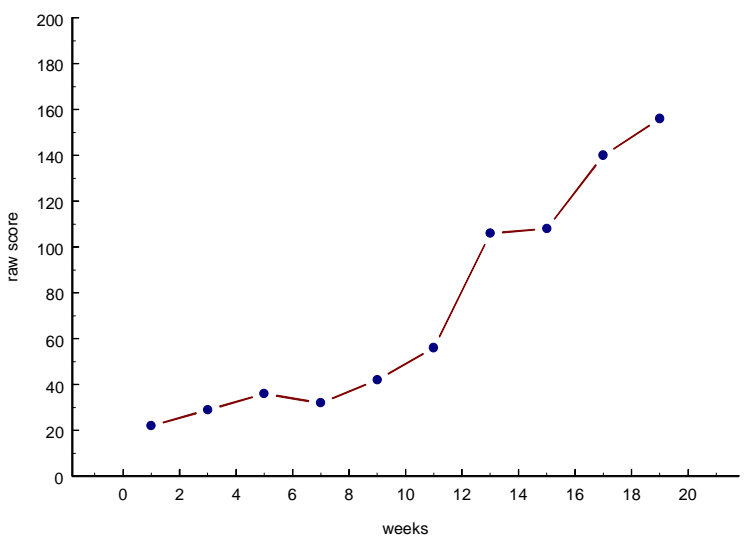

15

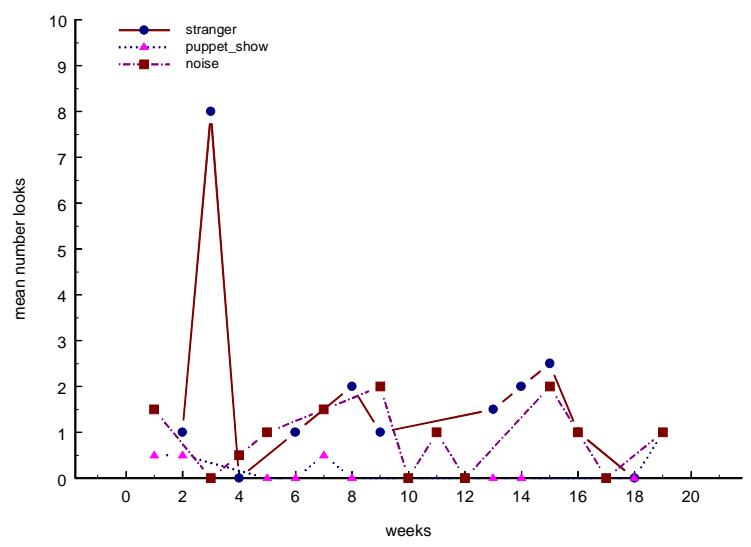

15



15



15

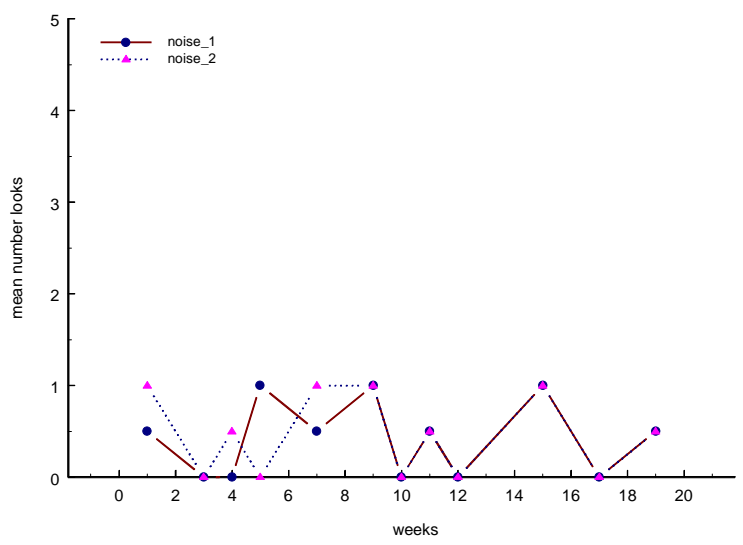

15



Figure 11. 